\title{
Reward Expectancy Strengthens CA1 Theta and Beta Band Synchronization and Hippocampal-Ventral Striatal Coupling
}

\author{
(10Carien S. Lansink, ${ }^{1,2}$ Guido T. Meijer, ${ }^{1}$ Jan V. Lankelma, ${ }^{1}$ Martin A. Vinck, ${ }^{1}$ OJadin C. Jackson, ${ }^{1}$ \\ and $\oplus_{C y r i e l}$ M.A. Pennartz ${ }^{1,2}$ \\ ${ }^{1}$ Swammerdam Institute for Life Sciences, Center for Neuroscience, Faculty of Science, University of Amsterdam, 1098 XH Amsterdam, The Netherlands, \\ and ${ }^{2}$ Amsterdam Brain and Cognition, Research Priority Program Brain and Cognition, University of Amsterdam, 1018 XA Amsterdam, The Netherlands
}

The use of information from the hippocampal memory system in motivated behavior depends on its communication with the ventral striatum. When an animal encounters cues that signal subsequent reward, its reward expectancy is raised. It is unknown, however, how this process affects hippocampal dynamics and their influence on target structures, such as ventral striatum. We show that, in rats, reward-predictive cues result in enhanced hippocampal theta and beta band rhythmic activity during subsequent action, compared with uncued goal-directed navigation. The beta band component, also labeled theta's harmonic, involves selective hippocampal CA1 cell groups showing frequency doubling of firing periodicity relative to theta rhythmicity and it partitions the theta cycle into segments showing clear versus poor spike timing organization. We found that theta phase precession occurred over a wider range than previously reported. This was apparent from spikes emitted near the peak of the theta cycle exhibiting large "phase precessing jumps" relative to spikes in foregoing cycles. Neither this phenomenon nor the regular manifestation of theta phase precession was affected by reward expectancy. Ventral striatal neuronal firing phase-locked not only to hippocampal theta, but also to beta band activity. Both hippocampus and ventral striatum showed increased synchronization between neuronal firing and local field potential activity during cued compared with uncued goal approaches. These results suggest that cue-triggered reward expectancy intensifies hippocampal output to target structures, such as the ventral striatum, by which the hippocampus may gain prioritized access to systems modulating motivated behaviors.

Key words: local field potential; motivation; navigation; nucleus accumbens; rhythm; tetrode

\section{Significance Statement}

Here we show that temporally discrete cues raising reward expectancy enhance both theta and beta band activity in the hippocampus once goal-directed navigation has been initiated. These rhythmic activities are associated with increased synchronization of neuronal firing patterns in the hippocampus and the connected ventral striatum. When transmitted to downstream target structures, this expectancy-related state of intensified processing in the hippocampus may modulate goal-directed action.

\section{Introduction}

The hippocampus is considered essential for episodic memory, which records personally experienced events ("what") in space

Received March 1, 2016; revised Aug. 23, 2016; accepted Aug. 24, 2016.

Author contributions: C.S.L. and C.M.A.P. designed research; C.S.L. and J.C.J. performed research; C.S.L., G.T.M., J.V.L., and M.A.V. contributed unpublished reagents/analytic tools; C.S.L., G.T.M., J.V.L., and J.C.J. analyzed data; C.S.L. and C.M.A.P. wrote the paper.

This work was supported by Human Frontier Science Program Grant RGP0127/2001, Netherlands Organization for Scientific Research VICI Grant 918.46.609, European Union Grant 270108, and Human Brain Project HBP SGA1 to C.M.A.P. and Netherlands Organization for Scientific Research VENI Grant 863.11.010 to C.S.L. Wethank Jeroen J. Bos for the use of rat hippocampal LFP data recorded during a pellet chasing task; Fernando Lopes da Silva for comments on the manuscript; Ole Jensen for general feedback; Kenneth D. Harris and A. David Redish for the availability of unit isolation software KlustaKwik and MClust, respectively is highly appreciated. We are grateful to Trevor W. Robbins, Barry J. Everitt, Rutsuko Ito, Carol A. Barnes and Bruce L. McNaughton for their help in designing the behavioral paradigm.

The authors declare no competing financial interests.

Correspondence should be addressed to Dr. Carien S. Lansink, Science Park 904, 1098 XH Amsterdam, The ("where") and time ("when") (Milner et al., 1998). An important basis for representing the spatiotemporal components of memory traces is the location-selective discharge of hippocampal neurons ("place cells") as rodents navigate through an environment (O'Keefe and Dostrovsky, 1971). By analyzing the firing rates of many place cells, the rat's position can be reconstructed (Wilson and McNaughton, 1993). The firing rates of hippocampal neurons are modulated by several other factors, such as environmental cues, task context, time, attentional processes, and motivational state (Muller and Kubie, 1987; Markus et al., 1995; Frank

Netherlands. E-mail: c.s.lansink@uva.nl. Martin A. Vinck's present address: Ernst Strüngmann Institute (ESI) for Neuroscience in Cooperation with Max Planck Society, Frankfurt, Germany. Jadin C. Jackson's present address: Medtronic, Inc. Minneapolis, MN 55432.

DOI:10.1523/JNEUROSCI.0682-16.2016

Copyright $\odot 2016$ the authors $\quad 0270-6474 / 16 / 3610598-13 \$ 15.00 / 0$ 
et al., 2000; Wood et al., 2000; Leutgeb et al., 2005; Kennedy and Shapiro, 2009; Fenton et al., 2010; Kraus et al., 2013). In addition to rate coding, hippocampal firing is temporally organized by mass activity in the theta band (in rodents: 6-12 Hz). As an animal traverses the place field of a given CA1 cell, its spikes are emitted first during later phases of the theta cycle, progressing to earlier phases when the distance traveled through the field increases (O'Keefe and Recce, 1993; Skaggs et al., 1996). Not only does this theta phase precession provide a means for refined spatial coding by including the distance traveled through the place field (Huxter et al., 2008; Cei et al., 2014), it also aligns activity of sequentially activated cells in a temporally compressed way and harbors a principle for predictive coding of future locations (Lisman and Redish, 2009). For individual neurons, the phase shift on theta cycles seems to be less reliable near the relatively silent peak phase of theta (Skaggs et al., 1996; Maurer et al., 2006). This phase may separate distinct theta sequences of assembly activity and may function as a "reset" allowing a new cycle of encoding and retrieval to begin (Hasselmo, 2005; Dragoi and Buzsáki, 2006). At the same time, this discontinuity in sequential firing is potentially problematic because it limits the length and continuity of memorized or predicted path representations and may degrade net effects of sequence-dependent synaptic plasticity in the network (compare Skaggs et al., 1996; Mehta et al., 2002).

The sequential activation of cell assemblies in the theta cycle is furthermore structured by $\gamma$ oscillations $(40-100 \mathrm{~Hz})$ nested within theta cycles (Bragin et al., 1995; Jensen and Lisman, 1996; Harris et al., 2003). In addition to theta and gamma rhythmicity, activity in the beta band $(15-35 \mathrm{~Hz})$ has been reported in hippocampus (Martin et al., 2007; Igarashi et al., 2014; Rangel et al., 2015). Beta band activity includes a first harmonic of theta, corresponding to twice the keynote frequency; these two terms will be used interchangeably here. Although its spectral power was found to depend on the animal's running speed (Terrazas et al., 2005), the behavioral correlates and functions of the hippocampal beta band activity during navigation remain largely unknown.

Hippocampal dynamics are mostly addressed during spatial exploration that is either spontaneous (Vanderwolf, 1969) or motivated by unpredictable, spatially scattered food reward ("pellet-chasing") (Wilson and McNaughton, 1993; Skaggs et al., 1996; Huxter et al., 2008). Little is known, however, about the effects of temporally specific changes in reward expectancy on hippocampal dynamics. Such changes take place when rewardpredictive cues are offered at discrete times during goal-directed navigation. Effects of motivationally salient cues on hippocampal place-field maps were highlighted previously (Lansink et al., 2012), but it remains to be examined how such cues affect rhythmic synchronization in the hippocampus and connected target structures. Especially the ventral striatum is considered a relevant output structure, as it integrates hippocampal information with inputs from the amygdala, prefrontal cortex, and thalamic nuclei (Pennartz et al., 1994; Voorn et al., 2004) and modulates behavioral output by generating reward-predictive firing (Apicella et al., 1991; Schultz et al., 1992; Pennartz et al., 2011).

Here, we first tested how reward-predictive cues that trigger goal-directed navigation affect hippocampal rhythmicity and phase coding compared with very similar, but uncued navigation. Second, we investigated how cue-driven motivational changes in hippocampal dynamics cohere with modulation of the ventral striatum as a key structure influencing goal approach (compare Dalley et al., 2005).

\section{Materials and Methods}

All experimental procedures were in accordance with the Dutch national guidelines on the conduct of animal experiments. The procedures and validation of the behavioral task, electrophysiological recordings, and data acquisition are described in detail previously (Lansink et al., 2012). Briefly, three male Wistar rats (300-450 g) were implanted with a dualbundle, 12 tetrode microdrive aiming for targets in the dorsal hippocampal area CA1 (4.0, $2.5 \mathrm{~mm}$ relative to bregma) and the ventral striatum $(-1.8,1.4 \mathrm{~mm}$ relative to bregma) (Lansink et al., 2007). Additional electrodes were positioned in the hippocampal fissure for recording local field potentials (LFPs) and in the corpus callosum overlying the hippocampus for referencing tetrode signals. A ground screw was inserted in the contralateral parietal bone. Histology and tetrode track reconstruction confirmed that hippocampal recording sites were in CA1 area and in ventral striatum; $78 \%$ of the ventral striatal recording sites were in the core and $22 \%$ in the shell region. Rats were kept on a reversed day-night cycle such that experiments were conducted in their active period. During the recording period, rats were food restricted to $85 \%-90 \%$ of their free-feeding weight.

\section{Behavior and data acquisition}

Implanted rats were trained to collect sucrose solution rewards by approaching and nose poking into a fluid well underneath an illuminated cue light in a fully automated, Y-shaped maze consisting of three identical chambers surrounding an equilateral center platform (Ito et al., 2008; Lansink et al., 2012). Each chamber contained three combinations of a cue light and a fluid well, one on each wall (see Fig. 1A). Nose pokes into the fluid wells were registered by interruption of infrared beams, which could trigger a solenoid valve system to deliver sucrose solution (15\%) into the fluid well. The rat's movement activity was tracked by 3 infrared beams per chamber, one of which was located at the chamber's entrance.

Naive rats learned to associate a discrete cue (i.e., the illumination of a cue light) and reward availability in daily sessions of 135 trials that each started with cue light presentation. In each 9 trial block, cue lights were presented once in random order. Nose poke responses $(>500 \mathrm{~ms})$ in the cued fluid well within $15 \mathrm{~s}$ following light onset were rewarded with sucrose solution $(70 \mu \mathrm{l})$, whereas responses to other fluid ports in this period were neither rewarded nor punished. Cue lights were dimmed after a random interval 1-4 s following fluid delivery or when the $15 \mathrm{~s}$ response period had elapsed and an intertrial interval started (10-20 s randomly selected). Intertrial interval duration doubled when rats failed to break the infrared beam between its current chamber and the central triangle. In intertrial interval periods, rats exhibited fluid well approach behaviors very similar to the periods when cues were illuminated, allowing comparison of neuronal activity patterns associated to cued versus noncued fluid well approaches. Rats were trained on this schedule until they performed above criterion (i.e., $90 \%$ correct responses on the first 90 trials in 3 consecutive sessions). Following this phase, rats were subjected to sessions in which the probability of reward after a correct nose poke depended on the spatial position of the chamber relative to environmental cues in the laboratory space. Reward probability was $75 \%$ for one of the chambers (" $75 \%$ chamber"), the location of which was different for each rat, whereas the other two chambers yielded reward in only $25 \%$ of the trials (" $25 \%$ chambers"). Reward was provided according to a pseudorandom schedule in which correctly performed trials were rewarded in 3 of 4 ( $75 \%$ chamber) or 1 of 4 ( $25 \%$ chambers) cue illuminations at a given fluid well. All other parameters were identical to the first set of sessions. The approach behavior of the rats as well as parameters, such as power, coherence (weighted phase lag index [WPLI]), spike-field coherence (pairwise phase consistency [PPC]), number of phase-locked units, and LFP phase coupling were not different in sessions using the probabilistic reward schedule compared with the $100 \%$ reward availability sessions, and all sessions were therefore pooled. A total of 23 sessions, in which rats performed above criterion, were included in our analysis ( 9 sessions with $100 \%$ reward availability and 14 under the probabilistic reward schedule). Analyses including single unit activity comprised 17 of these sessions ( 9 sessions with $100 \%$ reward probability and 8 under the probabilistic schedule). 
A

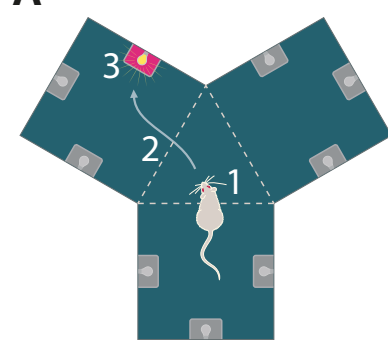

B

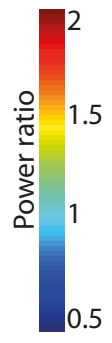

(1)

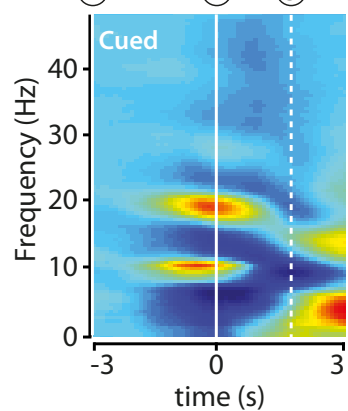

(2)

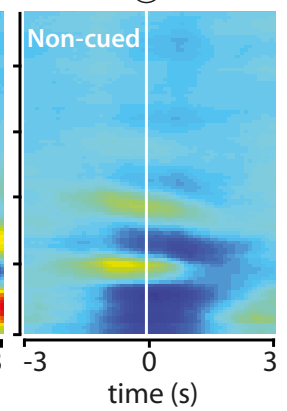

C

F

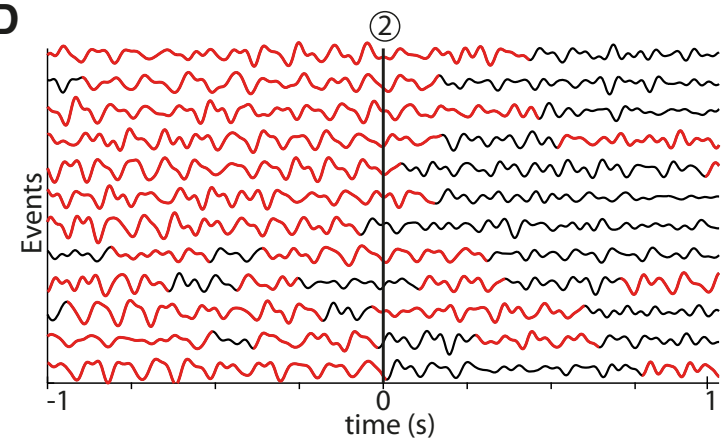

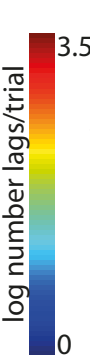
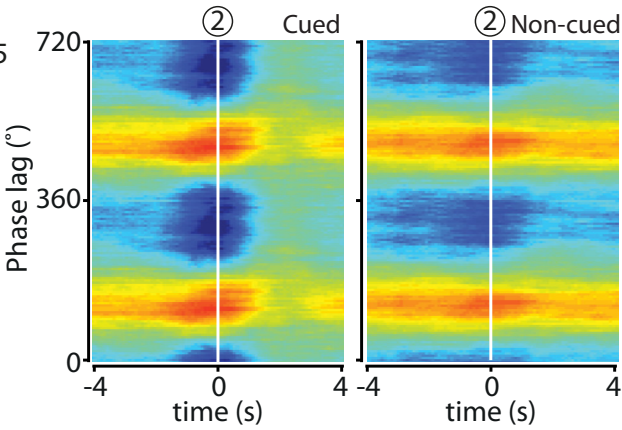

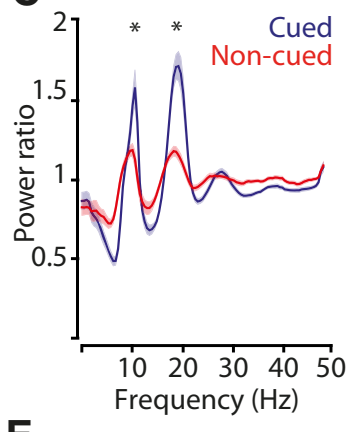

E

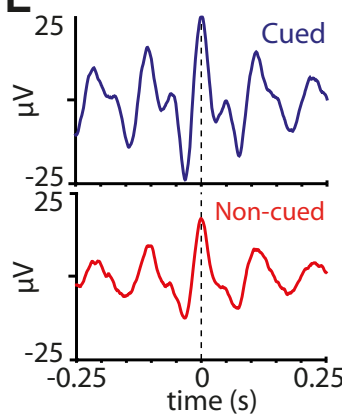

G

G

\section{.}

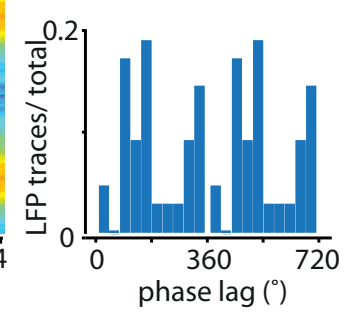

Figure 1. Increased power in hippocampal LFPs in the theta and beta range during cued reward-site approach. $A$, Y-maze and behavioral task. Cued fluid well approaches were initiated on cue light illumination (1), and comprised chamber entry (2; dashed line) and nose poke in the fluid well associated with the lit cue light followed by reward delivery (3). Noncued approaches involved steps 2 and 3 in the absence of an illuminated cue light and were not rewarded. B, Color-coded power spectrograms averaged across all recording sessions and aligned to chamber entry ( $2 ; n=23$ sessions). Power ratio was computed by dividing the absolute power by baseline power (see Materials and Methods). C, Mean power distributions for cued (blue) and noncued (red) approaches calculated over a time window of $1 \mathrm{~s}$ centered at chamber entry. Shaded areas represent SEM. ${ }^{*} p<0.002$ (WMPSR). D, Filtered ( $0-23 \mathrm{~Hz}$ ) single LFP traces recorded from the hippocampal CA1 pyramidal layer aligned to cued chamber entries (2). Red represents time segments in which the beta band power exceeded $0.15 \times$ maximum beta band power. Traces are a representative subsample from a single recording session. $\boldsymbol{E}$, Mean of all raw LFP waveforms synchronized on theta peaks occurring between $[-1,1]$ s relative to chamber entry events from the recording session shown in $\boldsymbol{D}$. $\boldsymbol{F}$, The phase lag between theta and beta band activity $\left(\varphi_{\text {lag }}=\varphi_{\beta}-2 \times \varphi_{\text {theta }}\right)$ within an LFP trace was relatively stable around chamber entries (2) in cued and noncued conditions. $G$, Distribution of beta-to-theta phase lags for all hippocampal LFP traces $(n=115)$. In this case, the phase delay corresponds to the distance between the theta peak and the beta peak appearing as a "shoulder" $\left(\sim 100^{\circ}\right)$. The phase delay of the second beta peak cannot be dissociated from the theta peak (compare Figs. 4, 6).

Neuronal activity, behavioral video tracking data, and photo-beam breaks were recorded using a 64 channel Cheetah data acquisition system (Neuralynx). Waveforms were saved in $1 \mathrm{~ms}$ windows each time the voltage signal exceeded a manually preset threshold ( $32 \mathrm{kHz}$; gain: $1000-$ $5000 \times$; filter settings: $600-6000 \mathrm{~Hz}$ ). LFPs were sampled continuously at a rate of $1690 \mathrm{~Hz}$ (gain 500; filter settings $1-475 \mathrm{~Hz}$ ). The rat's position was tracked with light-emitting diodes on the rat's head stage $(60$ frames $/ \mathrm{s}$; resolution of $0.4 \mathrm{~cm} / \mathrm{pixel}$ ).

Data analysis

Spike sorting. Individual units were identified on the basis of spike waveform events sharing similar waveform properties, including peak amplitude, energy, and principal components using automated and manual clustering software (KlustaKwik and MClust). Clusters of events were discarded if (1) they did not show a characteristic spike waveform or a consistent waveform profile across tetrode leads, (2) $>0.1 \%$ of the spike intervals was $<2 \mathrm{~ms}$, and (3) the number of events was $<50$. Putative interneurons were excluded from the dataset on the basis of firing rate
$(>8 \mathrm{~Hz})$ and waveform characteristics, such as low peak-to-valley width and valley shape (hippocampus: 2 units; ventral striatum: 3 units). A total of 194 hippocampal and 195 ventral striatal units were included in the analyzed dataset. All analyses were conducted with MATLAB (The MathWorks) using in-house developed software, the Chronux toolbox and FieldTrip (Oostenveld et al., 2011).

Power and coherence of LFPs. LFP traces were cleared of $50 \mathrm{~Hz}$ and its odd harmonics and rereferenced (i.e., the mean of all channels in a given structure was subtracted from the traces to minimize the influence of external oscillatory activity on power and coherence measures). A weighted average of power was computed by first taking the average metric over all channels per session. Each session mean was then multiplied by the number of behavioral events (e.g., chamber entries, cue illuminations) in the session, after which the mean power was computed over the grand sum of session means. The same procedure was followed for coherence.

Power. Time-frequency decompositions were constructed for $10 \mathrm{~s}$ intervals around chamber entries using the multitaper method from the 
Chronux toolbox in a time window of $2 \mathrm{~s}$ and a step size of $0.1 \mathrm{~s}$, resulting in a frequency resolution of $0.5 \mathrm{~Hz}$. The bandwidth product was 3.5 with 6 tapers. Background power was computed by taking the average power levels in a $5 \mathrm{~s}$ period before a cue light switched on and no (cued) nose poke event was registered. Relative power was computed by dividing the absolute power by the baseline resulting in a reference value of 1 .

Power spectral densities. These were estimated using Welch's method in windows of $2 \mathrm{~s}$ around theta peaks. Segments of the traces with 75\% overlap were transformed with a Hamming window and averaged. Normalization for comparison with theoretical harmonic values was performed by setting power in theta band to 1 . Multitaper methods yielded similar results.

Coherence. Coherence between LFPs was assessed with the WPLI (Vinck et al., 2011), which is relatively insensitive to volume conduction, noise, power variations, and sample size. For the hippocampal LFPs, similar results were obtained with conventional coherence measures and without rereferencing of the data. WPLI was estimated for a time window of $6 \mathrm{~s}$ surrounding chamber entry events by computing power and the cross-spectrum using a sliding window of $1 \mathrm{~s}$ with steps of $0.1 \mathrm{~s}$.

Velocity. The running speed of the rat was computed at each position (60 frames/s, step $0.016 \mathrm{~s}$ ) using the distance that the rat traveled in $0.05 \mathrm{~s}$ time windows. The mean $( \pm$ SEM) running speed across sessions for cued trials was $48.3 \pm 1.2 \mathrm{~cm} / \mathrm{s}$ and for noncued trials $37.0 \pm 1.0 \mathrm{~cm} / \mathrm{s}$ (Wicoxon's sum rank test, $p<10^{-5}$ ). To assess whether the differences in oscillatory activity in cued versus noncued trials could be ascribed to the running speed of the rats, power and coherence (WPLI) across sessions were recomputed as described above for velocity-matched trials between cued and noncued conditions. Using a sampling-withoutreplacement procedure, cued trials were paired to noncued trials from the same session showing the least mean velocity difference over an interval of $1 \mathrm{~s}$ surrounding chamber entry. Trial pairs with a velocity difference $>5 \mathrm{~cm} / \mathrm{s}$ were excluded. This procedure included a total of 1684 trial pairs ( $73 \pm 3$ trials/session; $n=23$ sessions). In a subsequent analysis using velocity-matched trial pairs, the mean $( \pm$ SEM) running speed across sessions was $31.1 \pm 0.9 \mathrm{~cm} / \mathrm{s}$ for cued trials and $31.4 \pm 0.9 \mathrm{~cm} / \mathrm{s}$ for noncued trials (Wilcoxon's matched-pairs signed-rank test [WMPSR], not significant).

Firing rate modulation by oscillations. Modulation of a unit's firing rate by oscillations was determined by first filtering the LFP traces recorded from the hippocampal fissure using a Chebyshev Type 1 bandpass filter between 6 and $12 \mathrm{~Hz}$ for the theta band and between 15 and $20 \mathrm{~Hz}$ for the beta band. The analysis included spikes in periods in which the power in the theta or beta band divided by the total power $(1-250 \mathrm{~Hz})$ was $\geq 0.1$. Binned spikes $\left(15^{\circ} / \mathrm{bin}\right)$ were then plotted relative to two successive periods of theta or beta oscillations ( $0^{\circ}$ corresponds to the peak of the cycle). Peaks and troughs in the firing phase histograms were determined with the locfit curve fitting method (Chronux toolbox). The phase angles for the first and, if applicable, second peak were determined by taking the mean of all phase values between the troughs flanking the peak. Spike distributions were tested for nonuniformity over the phase interval of the peak with the Rayleigh test.

Beta-theta phase relations. Phase phase relationships between theta and beta band (or first harmonic) activity were determined by plotting each spike time in a session as a function of beta versus theta phase. The phase of beta is expected to change about twice as fast as the theta phase; therefore, it is assumed that the cloud of spike phase data points per session can be approximated by a line with a slope of $\arctan (2)$ and a certain offset. The phase lag of beta with respect to theta is $\varphi_{\text {lag }}=\varphi_{\text {beta }}-$ $2 \times \varphi_{\text {theta. }}$

Spike-LFP coherence. The phase between spiking activity and the LFP recorded in the hippocampal fissure was investigated using the PPC measure (Vinck et al., 2010, 2012). The LFP was filtered using a Hanning window with a length of 5 cycles per frequency step of $1 \mathrm{~Hz}$. For every frequency unit, the instantaneous LFP phase was computed for all possible time points through convolution, allowing to readily extract the phases of individual spikes. The PPC was computed for all pairs of spikes in a time window of $6 \mathrm{~s}$ synchronized on cued or spontaneous chamber entries. Time-frequency representations were generated using a $500 \mathrm{~ms}$ sliding window with a step size of $10 \mathrm{~ms}$ and included for each window
A
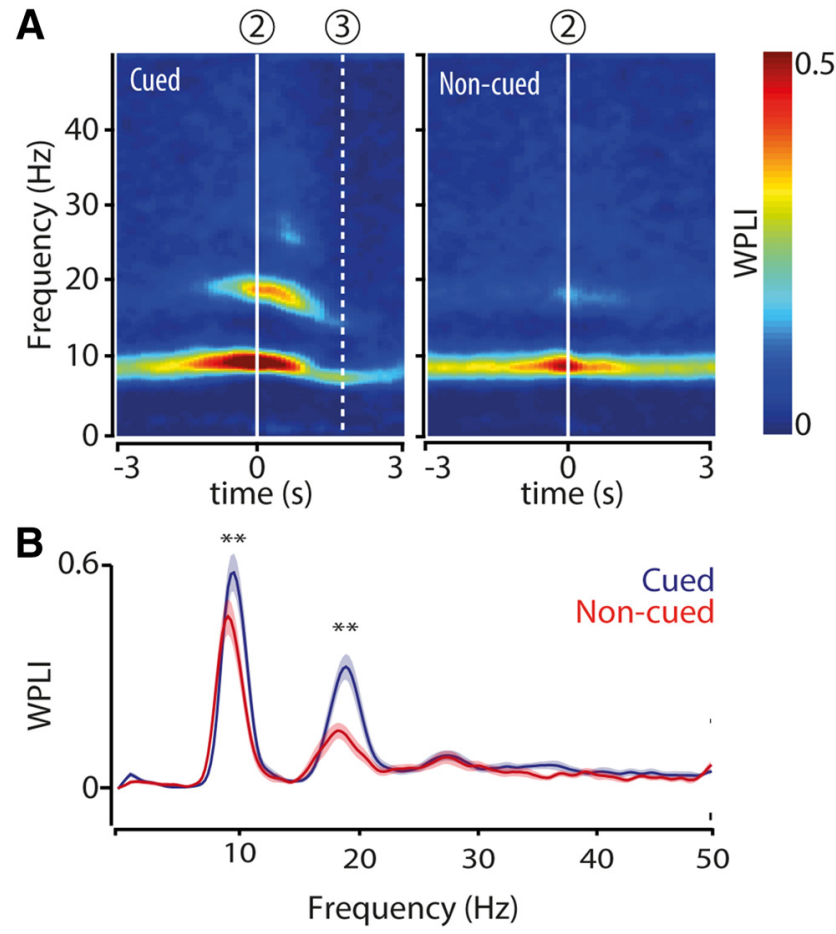

Figure 2. Theta and beta band coherence between hippocampal LFPs peaks at chamber entry during cued and noncued reward approaches. $\boldsymbol{A}$, Color-coded time-frequency plots represent mean coherence (WPLI) of hippocampal LFPs computed across all tetrodes $(n=5)$ in the pyramidal cell layer and recording sessions $(n=23)$ and synchronized on chamber entry (2). Dashed line (3) indicates mean nose poke time relative to chamber entry. $\boldsymbol{B}$, Mean WPLI distributions for cued (blue) and noncued (red) approaches calculated over a time window of $1 \mathrm{~s}$ centered at chamber entry. Shaded areas represent SEM; $n=23$ sessions. ${ }^{* *} p<10^{-4}$ (WMPSR).

neurons that fired at least 50 spikes in that window. PPC traces were computed for a $1 \mathrm{~s}$ time window centered on cued or spontaneous chamber entries and included neurons firing $\geq 50$ spikes in both conditions. Statistical differences between conditions were assessed with WMPSR $(p<0.05)$.

Phase precession. Position data of the rat were linearized for the three Y-maze chambers by first rotating the $(x, y)$ position samples in each chamber such that all chambers overlapped in a common projected space and then by collapsing the $y$-coordinates such that the approach to each separate reward site was represented by one linear path. The spikes that were generated in a $2 \mathrm{~s}$ time window surrounding chamber entries were mapped to the linearized path. The centers of the firing fields of neurons were identified by first binning the path into segments of 10 pixels $/ 4 \mathrm{~cm}$ and then by identifying the bin with the maximum firing rate, labeled the place field center. The borders of the firing fields were determined by the first bin relative to the maximal firing rate bin to each site that contained less spikes than $10 \%$ of the maximal firing rate bin. Position values corresponding to the included spikes were scaled between -1 and 1 .

Spike phase. The LFP trace recorded at the hippocampal fissure was bandpass filtered using a zero phase lag forward and reverse first-order Butterworth filter ( $8-12 \mathrm{~Hz}$ for theta, $15-20 \mathrm{~Hz}$ for beta). The phase of individual spikes was extracted from the Hilbert transform of the filtered LFP trace for theta and beta. A phase of $0^{\circ}$ corresponds to the peak of the LFP and $180^{\circ}$ to the trough following the peak. Beta cycles were partitioned in 2 groups, beta- 1 contained the cycles that closely aligned the rising slope of theta and beta- 2 were the cycles that approximately ran along the falling slope of theta (see Figure $6 A$, right).

Phase precession. A circular regression line was fit to the spike phase plots as described by Kempter et al. (2012); the angle of the fitted circular regression line was limited between 0 and -1 . A neuron was classified as phase precessing when there was a significant $(p<0.05)$ linear-circular correlation between spike phase and linearized posi- 


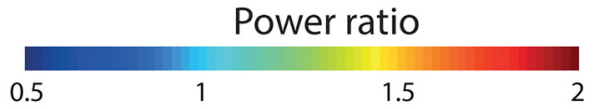

A Cue onset
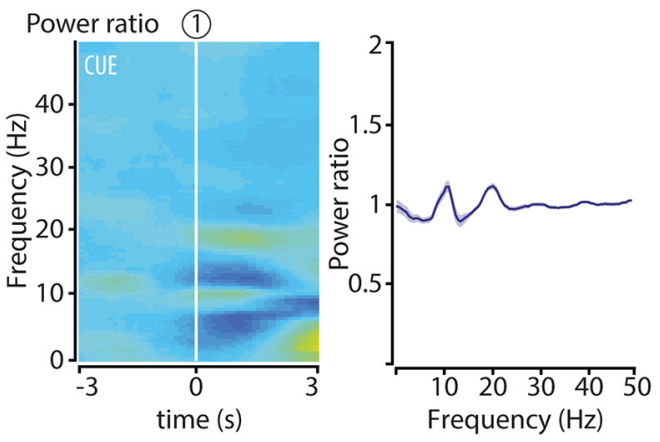

C Experience dependence

(2) Power ratio
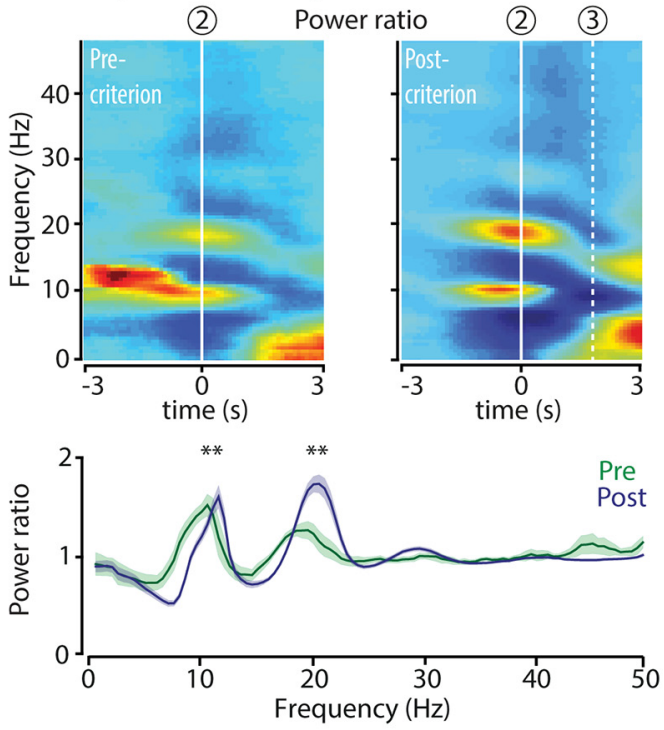

E Velocity-matched trials

(2)
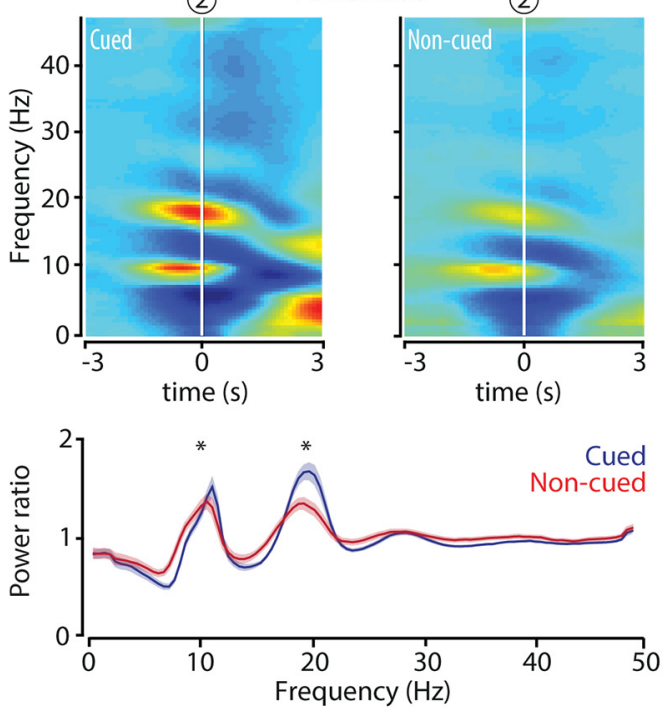

WPLI

0 0.5

B
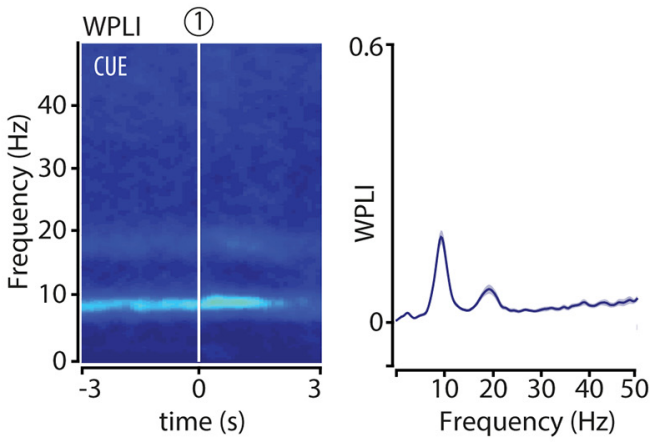

D

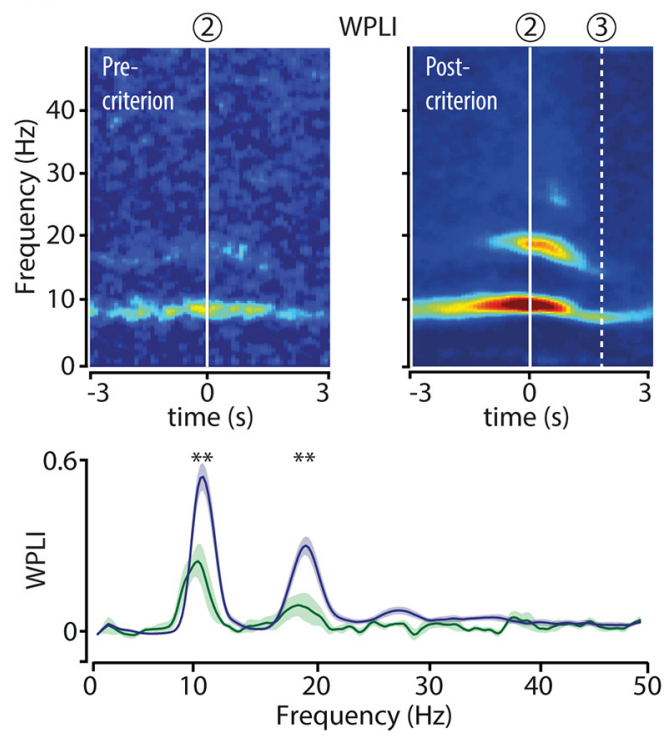

$\mathbf{F}$

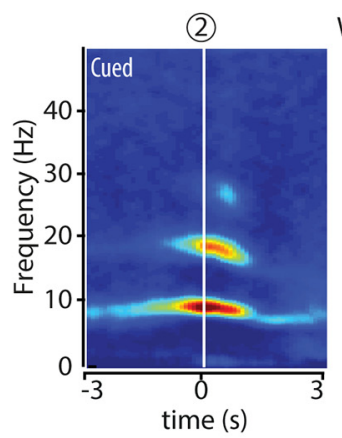

WPLI
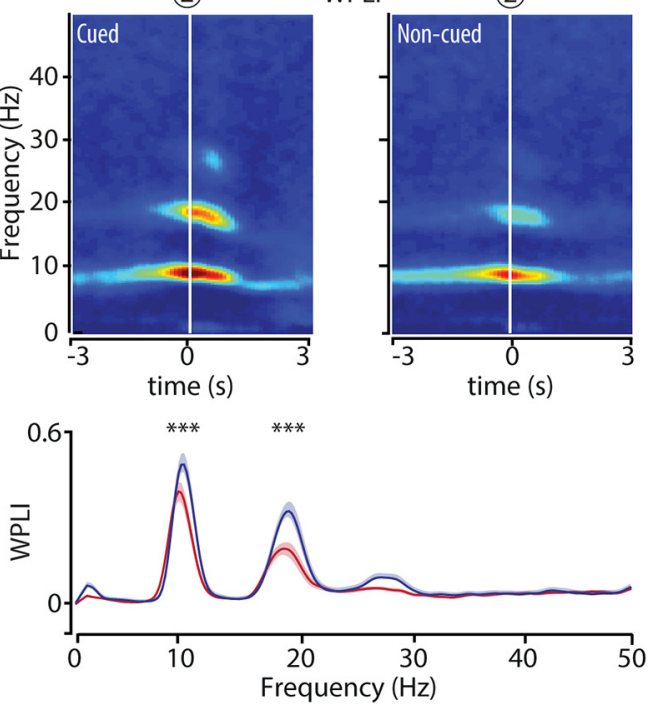

Figure 3. Analyses controlling for synchronization to cue onset, experience dependence, and effects of locomotion velocity. $\boldsymbol{A}$, Hippocampal theta and beta bad power and coherence are not strongly associated with cue onset. Left, Color-coded time-frequency plot of power of hippocampal LFPs averaged across all recording sessions and aligned to cue onset ( $1 ; n=23$ sessions). Right, Power ratio as a function of frequency (mean \pm SEM) for cued approaches calculated over a time window of $1 \mathrm{~s}$ centered at cue onset. $\boldsymbol{B}$, Same as in $\boldsymbol{A}$ but now for coherence (WPLI). Power and WPLI increases in the theta and beta band aligned to cue onset are weaker than the increases related to chamber entries (Fig. 1, 2), indicating that cue illumination (Figure legend continues.) 
tion, when the slope of the fitted regression line fell within -0.05 and -0.75 and with $R^{2}>0.2$.

Peak phase spikes. Peak phase spikes were defined as occurring in the phase range of $\left[-40^{\circ}, 40^{\circ}\right]$ relative to the theta peak and emitted after the rat passed one-fourth of the firing field (i.e., the normalized position of the rat was between $[-0.5,1]$, where $[-1,1]$ is defined as the full firing field). Similar results were obtained when different phase ranges was used to select peak phase spikes (e.g., $\left[-20^{\circ}, 20^{\circ}\right]$ ).

\section{Results}

\section{Reward cues enhance theta band activity and trigger beta band activity}

We first examined LFPs recorded near the hippocampal fissure and in the CA1 pyramidal layer from rats performing a visually cued goal-approach task in a Y-shaped maze (Ito et al., 2008; Lansink et al., 2012) (Fig. 1A). Situated around a triangular central platform, each of the three Y-maze chambers harbored three cue lights with reward ports underneath. At illumination of a cue light, conditioned rats readily initiated an approach response from their self-chosen location in the maze to the illuminated goal site, where they briefly waited before a sucrose-solution reward was delivered. When the cue light switched off, rats often initiated further approach responses, now to nonilluminated goal sites. This allowed us to contrast oscillatory patterns exhibited during virtually identical behaviors; namely, approaches that were driven by temporally discrete cues raising reward expectancy versus noncued (i.e., spontaneous) approaches.

Power in the theta $(6-10 \mathrm{~Hz})$ and beta $(15-20 \mathrm{~Hz})$ bands was significantly higher during cued than noncued approaches. In both situations, however, the changes in these frequency bands showed approximately the same temporal relation to task events (Fig. $1 B, C$ ). Power in the theta band peaked just before the rat entered the cued chamber, whereas beta band power peaked at chamber entry and declined to baseline before the rat reached the goal site. The relationship between changes in theta and beta band and power was highly nonlinear, which was apparent from the significantly larger relative power difference between cued and noncued conditions for beta than for theta band activity (Fig. $1 C$; ratio of average power in cued to noncued conditions for theta: $1.14 \pm 0.03$ and for beta $1.33 \pm 0.03$; WMPSR; $p<2 \times$ $\left.10^{-4}\right)$. In real-time LFP traces, beta band activity was recognizable as "shoulders" on theta peaks (Fig. 1D,E). Analyses of peak-triggered averages of raw hippocampal theta oscillations

$\leftarrow$

(Figure legend continued.) does not account for the onset of the power and coherence increments observed near chamber entries. $p<0.01$ (WMPSR). $C, D$, Strength of hippocampal theta and beta band power and coherence increases with experience. Top panels, Color-coded timefrequency plots represent power ratio $(\boldsymbol{C})$ and WPLI (D), respectively, relative to chamber entry (2). Color scale is the same as in $\boldsymbol{A}, \boldsymbol{B}$. In precriterion sessions, rats approached the cued well in $<90 \%$ of the trials ( $n=8$ sessions); whereas in postcriterion sessions, rats performed $>90 \%$ of the trials correctly ( $n=9$ sessions). All of these sessions belonged to the primary cue conditioning phase, where every correct goal approach resulted in reward delivery. Bottom panels, Power ratio and coherence (mean \pm SEM) as a function of frequency, for cued approaches centered at chamber entry (2). ${ }^{* *} p<0.02$ (WMPSR). $\boldsymbol{E}, \boldsymbol{F}$, Differences in running speed do not account for differences in hippocampal theta and beta band power and coherence between cued and noncued chamber entries. In a reanalysis of power and coherence, cued and noncued trials were velocity-matched by pairing cued trials to noncued trials from the same session showing the least mean velocity difference across an interval of $1 \mathrm{~s}$ surrounding chamber entry. Top panels, Time-frequency plots of power ratio $(\boldsymbol{E})$ and WPLI $(\boldsymbol{F})$ synchronized on chamber entry (2) for velocity-matched trials in cued and noncued conditions. Color scale is the same as in $\boldsymbol{A}, \boldsymbol{B}$. Bottom panels, The peak power ratio and peak coherence (mean \pm SEM) in the theta and beta ranges (2) were significantly stronger for cued than for noncued approaches. ${ }^{*} p<$ 0.03 (WMPSR). ${ }^{* *} p=10^{-4}$ (WMPSR). These results render the possibility that our results can be explained by a velocity difference between conditions unlikely. confirmed this profile, expressing beta activity peaks as being, at least in part, out of phase with the main theta peaks (Fig. 1E). The enhancement of beta band activity during cued approaches was, however, not limited to the falling phase of theta, as will be indicated below, which is in agreement with the (approximately) theta-doubled frequency observed in Figure $1 B, C$. Theta and beta frequency oscillations maintained a stable phase relationship, which was apparent from the relatively constant phase delay within hippocampal traces across time in both cued and noncued conditions (Fig. 1F, G).

No significant power differences were detected in the $\gamma$ range $(30-100 \mathrm{~Hz})$ in relation to chamber entries.

\section{Cued goal approach strengthens hippocampal synchronization}

Communication between neuronal populations may be regulated by rhythmic synchronization within and between multiarea networks (Engel et al., 1991; Fries, 2005; Bosman et al., 2014). We tested whether the increase in theta and beta power was paralleled by strengthened synchronization between hippocampal LFPs, recorded at different sites across the dorsal CA1 pyramidal cell layer using the WPLI (Vinck et al., 2011). This coherence measure is relatively insensitive to volume conduction, noise, power variations, and sample size. As for power, the hippocampal WPLI for the theta and beta band peaked when the rat entered a chamber and was significantly stronger for cued than for noncued chamber entries (Fig. 2A,B).

For both frequency bands, the increases in power and coherence (WPLI) were not aligned to cue onset (Fig. $1 B$, " 1 "), which was the earliest predictor of upcoming reward, but started on average about a second later, approximately upon chamber entry. Indeed, when power and WPLI were aligned to cue onset, the increases were more dispersed in time, indicating that cue onset itself is not strongly modulating oscillatory synchronization (Fig. $3 A, B)$

By itself, the increase in theta and beta power could result from the attribution of reward value to the cue-action sequence by associative learning, or from the physical change of cue light illumination. We addressed this question by contrasting sessions in which rats were learning the task (responding correctly to $<$ $90 \%$ of cue light illuminations; precriterion sessions) to sessions in which rats were highly proficient in task execution $(>90 \%$ correct responses to cue lights; postcriterion sessions). Theta and especially beta band power increased more strongly for cued approaches in postcriterion compared with precriterion sessions, confirming a learning effect (Fig. 3C). In line with the learning effect on spectral power, the increase in hippocampal WPLI in the theta and beta range was stronger in postcriterion than precriterion sessions (Fig. 3D).

Theta and beta band activity has been reported to rise with locomotion velocity (see Terrazas et al. (2005), referring to changes in the first harmonic of theta. Other studies showed, however, that only a small fraction of the variance in the power and coherence of theta could be explained by running speed and that these theta features varied more strongly with other aspects of behavioral tasks (Wyble et al., 2004; Montgomery et al., 2009). To test whether differences between cued and noncued approaches can be ascribed to such an effect, we recomputed spectral power and WPLI for cued and noncued trials that were matched for velocity. Under these conditions, the peak power and peak coherence in the theta and beta range were also significantly stronger for cued than for noncued approaches, which 
A Hippocampus

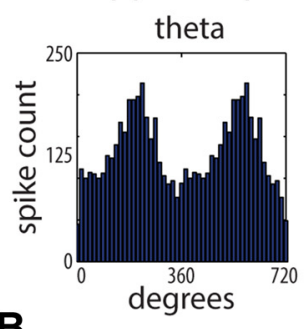

B

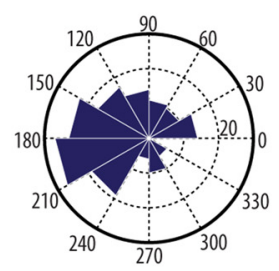

$158 / 194$
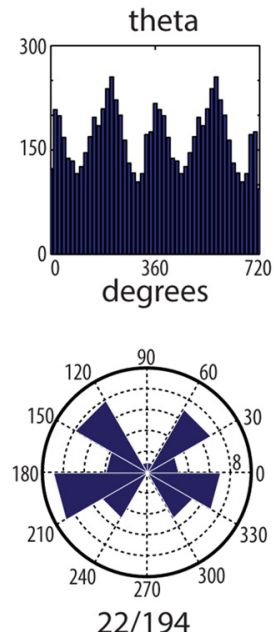

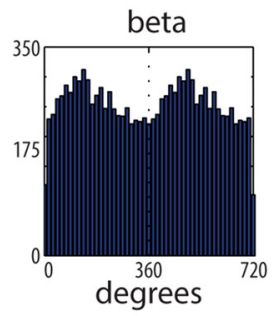

C
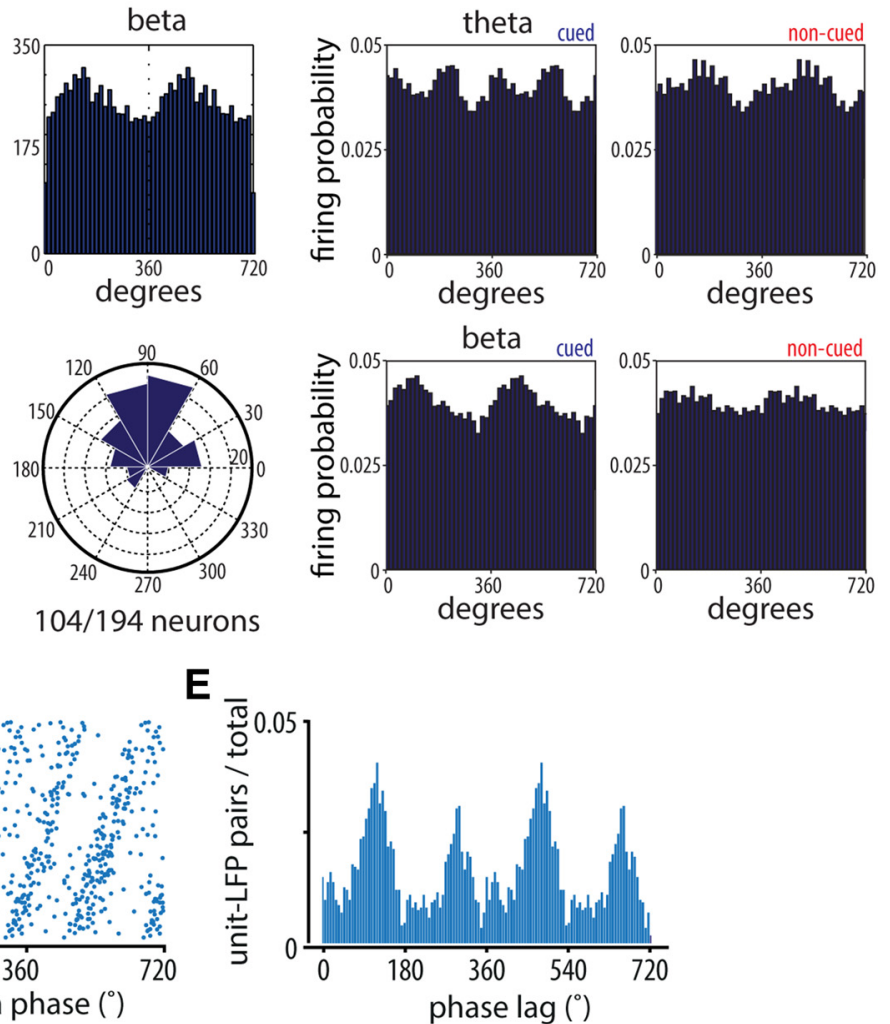

$\mathbf{E}$
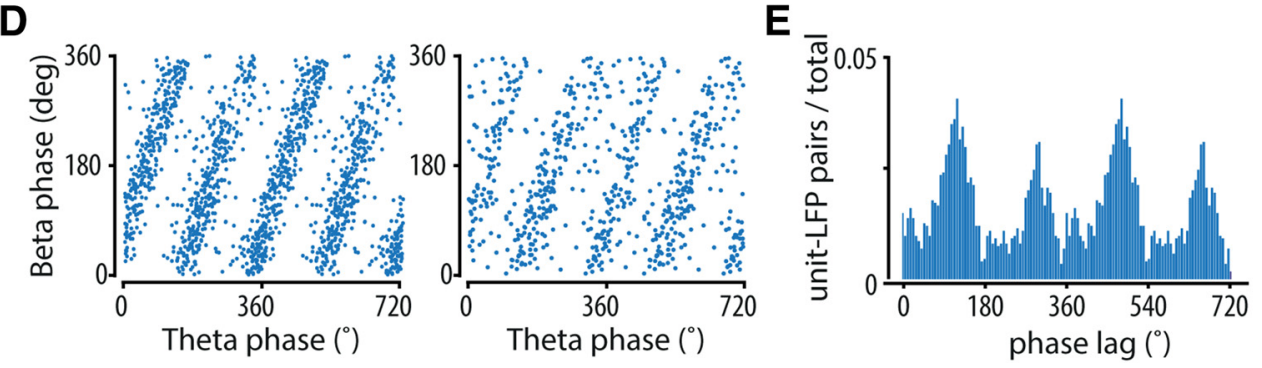

Figure 4. Hippocampal spikes phase lock to theta and beta band activity. A, Phase distributions of example hippocampal units relative to theta $(6-12 \mathrm{~Hz})$. Left, Middle, beta (15-20 Hz; right) LFP cycles recorded near the hippocampal fissure. The LFP peak of theta oscillations here and elsewhere in this paper is $0^{\circ}$. B, Distributions of preferred firing angles of all significantly phase-locked units per frequency range. Ratios below polar plots indicate the fraction of significantly phase-locked units in the total recorded population. Significant phase locking was assessed with the Rayleigh test. $p<10^{-20}$. C, Population phase distributions of hippocampal units showing significant phase locking to theta $(6-12 \mathrm{~Hz}$; top panels) and beta ( $15-20 \mathrm{~Hz}$; bottom panels) for cued and noncued conditions. LFP cycles recorded near the hippocampal fissure. Two peaks were detected in the theta cued condition $\left(38.5^{\circ}\right.$ and $215^{\circ}$; Rayleigh test, $\left.p<10^{-10}\right)$ and one in the noncued condition $\left(183^{\circ}\right.$; Rayleigh test, $\left.p<10^{-6}\right)$. For beta, one peak was detected in the cued condition $\left(65.2^{\circ}\right.$; Rayleigh test, $\left.p<10^{-6}\right)$ and none in the noncued condition. $D$, Two examples of hippocampal units for which the firing phase of each spike recorded in the session to LFP beta cycles was plotted against its phase to LFP theta cycles. $E$, Distribution of beta-to-theta phase lags $\left(\varphi_{\text {lag }}=\varphi_{\text {beta }}-2 \times\right.$ $\left.\varphi_{\text {theta }}\right)$ for all unit-LFP pairs expressed as fraction of the total number of pairs $\left(n=1750\right.$ pairs; median phase delays $107^{\circ}$ and $\left.288^{\circ}\right)$.

renders a confound arising from a velocity difference unlikely (Fig. $3 E, F)$.

\section{Beta band activity affects local hippocampal firing}

We next examined whether the cue-induced enhancement in hippocampal LFP synchrony is locally relevant and thus affects CA1 spiking. The majority of $194 \mathrm{CA} 1$ neurons showed general firing modulation by the theta rhythm (i.e., they showed one preferred firing phase during one theta cycle; $n=158 ; 81 \%$; Fig. $4 A, B$, left). Another subset of neurons showed two significant preferred firing phases in one theta cycle, indicating an additional beta band-specific firing modulation (Fig. $4 A, B$, middle; $n=22$; $11 \%)$. When the spiking of neurons was related to LFP traces filtered in the beta band $(15-20 \mathrm{~Hz}), 54 \%$ of the neurons $(n=104$ of 194) showed a significant preferred firing phase (Fig. $4 A, B$, right). Together, these results indicate that a subset of cells preferably fire on one of two beta cycles included in a theta period and other cells fire on each beta cycle (Fig. 4A,B). Population histograms of all cells that exhibited significant phase locking to theta oscillations in the cued condition showed two peaks, in line with the "shoulders" and humps identified in the averages of raw LFP traces (Rayleigh test, $p<10^{-10}$ ) (Mizuseki et al., 2009), whereas in the noncued condition only one peak was present (Fig. 4C, top; Rayleigh test, $p<10^{-6}$ ). Correspondingly, firing probability across the CA1 population exhibited a significant peak to beta band activity in the cued but not uncued condition (Fig. 4C, bottom; Rayleigh test, $p<10^{-6}$ ). Spike locking to beta band activity was consistently related to theta locking as appeared from the linear relationship between the phases of single-unit spikes relative to theta and beta cycles, respectively (Fig. $4 D$ ). The median phase delays of beta band activity across all recorded spikeLFP pairs were $107^{\circ}$ and $288^{\circ}$ relative to the theta cycle (Fig. $4 E$ ). This result helps to better understand the manifestation of beta activity in hippocampal LFPs (Figs. 1, 2). First, the phase lags of the LFP beta shoulders in between theta peaks (at $\sim 100^{\circ}$; Fig. $1 F$ ) nicely align with the first spike peak at $107^{\circ}$ (Fig. $4 E$ ). Second, that a second distinct beta peak is not clearly visible in the smoothed raw LFP (Fig. $1 D, E$ ) can be understood from the finding that the second (spiking) peak ( $\sim 288^{\circ}$; Fig. $\left.4 E\right)$ lies close to the theta peak $\left(0\right.$ or $360^{\circ}$; compare Fig. $\left.1 F\right)$.

To probe the temporal evolution of hippocampal firing modulation by LFPs across the task sequence, we assessed spike-field coherence with the PPC measure, which is not biased by sample size effects (Vinck et al., 2010, 2012). Spike-field coherence in the theta and beta bands was most prominent at chamber entry and shortly thereafter, and was significantly elevated in cued versus noncued goal-site approaches (Fig. 5A,B). 
A

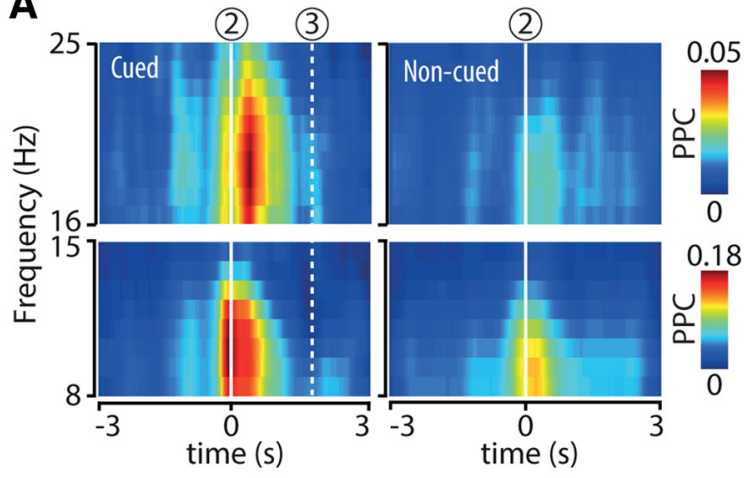

B

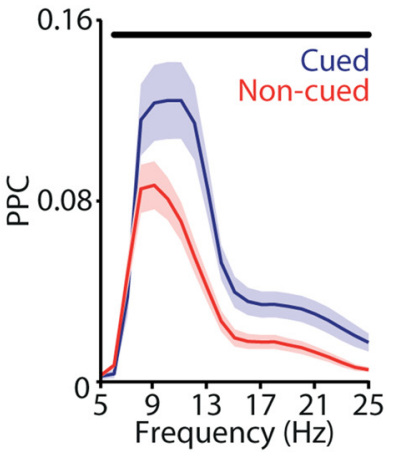

Figure 5. Hippocampal phase locking to theta and beta band activity at cued chamber entries. $A$, Color-coded time-frequency plots represent mean spike-field coherence (PPC) across all recorded sessions $(n=23)$ aligned to chamber entry (2). Dashed line (3) indicates mean nose poke time relative to chamber entry. $\boldsymbol{B}$, PPC distributions as a function of frequency (mean \pm SEM) for cued (blue) and noncued (red) approaches calculated over a time window of $1 \mathrm{~s}$ centered at chamber entry. Horizontal black bar represents a significant difference between conditions (WMPSR; $p<0.05$ ).
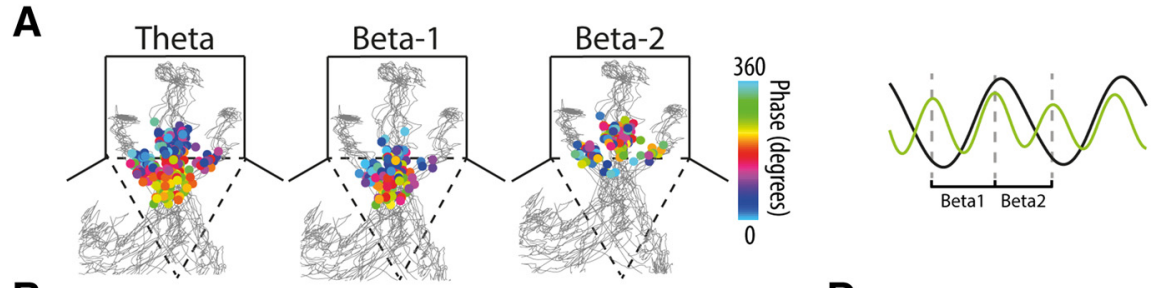

B
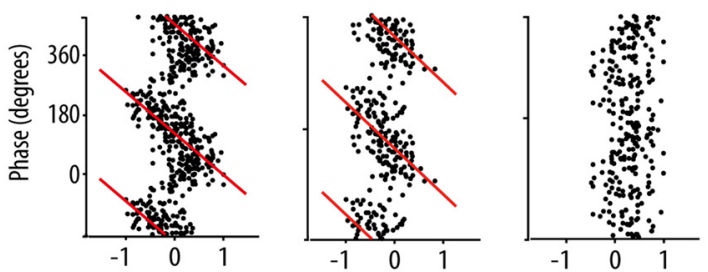

D
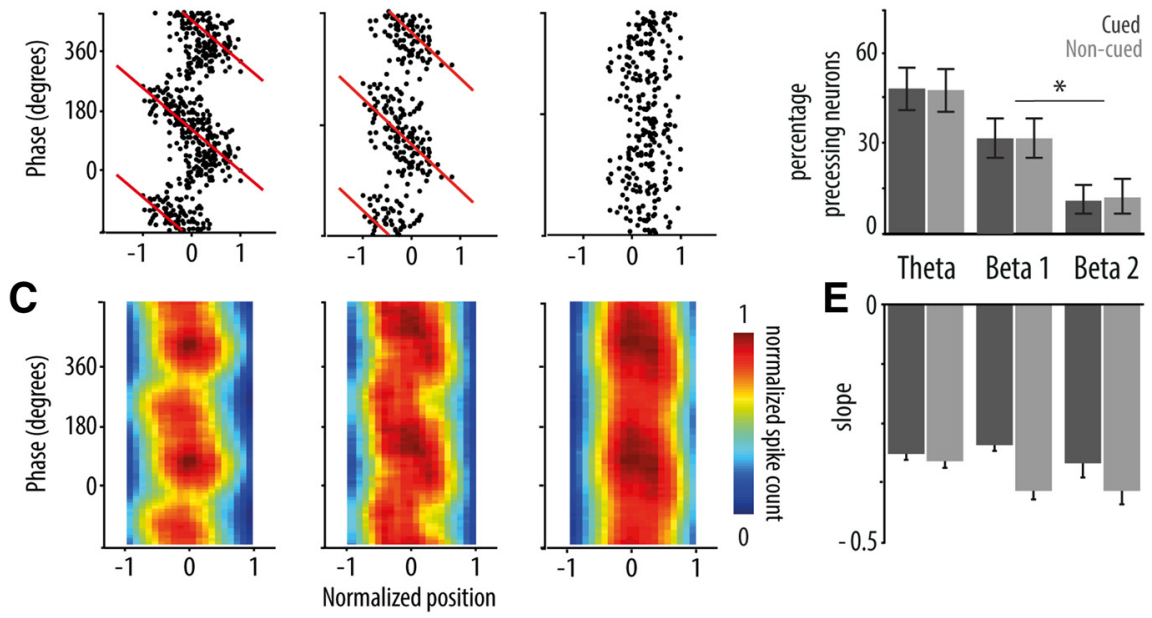

Figure 6. Hippocampal phase precession is not affected by reward expectancy. $A$, The spatial distributions of spike phases of a hippocampal neuron relative to cycles of theta (left), beta- 1 (middle), and beta-2 (right). Right, Inset, Relation of beta- 1 and beta- 2 (green) with theta (black) in filtered and smoothed LFP traces. Spikes are plotted on top of the rat's trajectories (gray) to each of three fluid wells in the chambers and are color-coded for phase (peak of cycle is $0^{\circ}$; time interval: $4 \mathrm{~s}$ centered on chamber entry [dashed line]; all chambers are pooled (see Materials and Methods). Precession on theta and beta-1 appears as a gradual shift in color as the rat moves through the chamber toward the goal location. This example neuron does not show phase precession on beta-2. $\boldsymbol{B}$, Firing phase of spikes as a function of linearized and normalized position of the example neuron shown in $\boldsymbol{A}$. Red represents the fitted circular regression line, the slope of which indicates precession strength. $\boldsymbol{C}$, Color-coded phase position plots represent the mean normalized spike density distribution per type of cycle across all neurons exhibiting significant precession in at least one of the three types (i.e., theta, beta-1, and/or beta-2). D, Percentage of significantly phase precessing CA1 units of a total of 194. Error bars indicate $2.5-97.5$ percentile intervals based on a test of binomial proportion. ${ }^{*} p<0.05$. The proportion of neurons precessing on beta- 1 was significantly larger than that precessing on beta-2. $E$, Mean slope ( \pm SEM) of the fitted regression lines of phase versus position for all significantly phase precessing units (WMPSR, not significant).

by cue-driven reward expectancy and accompanying beta band activity has remained open. We assessed phase precession by plotting theta- and beta-referenced phases of hippocampal spikes as a function of the animal's position during cued and noncued approaches (Fig. 6A-C). Beta cycles were considered running from peak to peak; beta- 1 is the cycle that closely aligns to the rising slope of theta, and beta- 2 is the cycle that approximately runs along the falling slope of theta; Figure $6 \mathrm{~A}$, right). While confirming significant theta phase precession (94 of 194 neurons, $48 \%$ ), we also report beta phase precession for a substantial fraction of hippocampal neurons (Fig. 6D). A significantly larger fraction of neurons precessed on the beta cycle that is closely aligned to the rising theta slope (beta-1; 61 of 194 neurons, 31\%) compared with the cycle that accompanies theta's falling slope (beta-2; 22 of 194 neurons; 11\%). This bimodality of phase precession is consistent with existing evidence (Skaggs et al., 1996; Yamaguchi et al., 2002; Maurer et al., 2006). In combination with the stable phase relation between theta and beta band activity (Fig. $1 F, G$ ), this result indicates that beta phase precession should be considered a straightforward reflection of theta phase precession. Thus, phase precession on beta cycles is not independent from theta phase precession, but it does offer temporal delineation of theta phase precession segments by way of LFP and corresponding spike dynamics (Fig. 4).

Given the distinction in phase precession associated with the rising and falling slope, we asked whether theta phase precession is resilient against variations in reward expectancy. A similar number of neurons showed precession in the noncued (93 of 194 neurons; 48\%) compared with cued conditions (94 of 194 neurons; $48 \%$; Fig. $6 D$ ) and the proportion of rising and falling slope precessing neurons was the same in both conditions (cued: beta-1: 61 of 194 neurons; 31\%; beta-2: 22 of 194 neurons; $11 \%$; noncued: beta-1: 61 of 194 neurons; $31 \%$; beta-2: 24 of 194 neurons; $12 \%$; Fig. $6 D$ ). When comparing cued versus uncued condions, the mean slopes of the fitted regression lines of phase versus position, computed across all significantly phase precessing units, were not significantly different (WMPSR), indicating similar precession rates across conditions.

\section{Phase precession and spikes emitted at the peak phase of theta}

Theta phase precession temporally organizes hippocampal firing (O'Keefe and Recce, 1993; Skaggs and McNaughton, 1996), but thus far the question of whether phase precession is modulated
Many spikes that were emitted from the same spatial position emerged at two different phases of theta cycles: namely, the descending phase and the peak (Fig. 7 A,B) (Maurer et al., 2006). The precise temporal organization of firing around the falling slope of theta may therefore not be fully classified with the stan- 
A

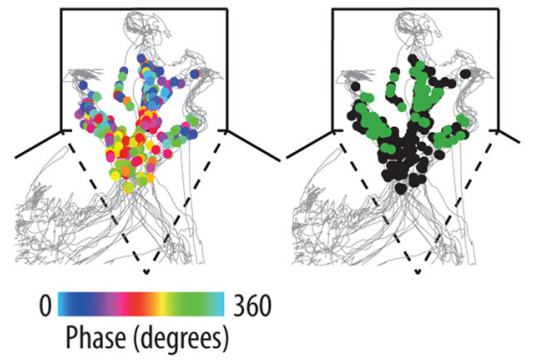

B
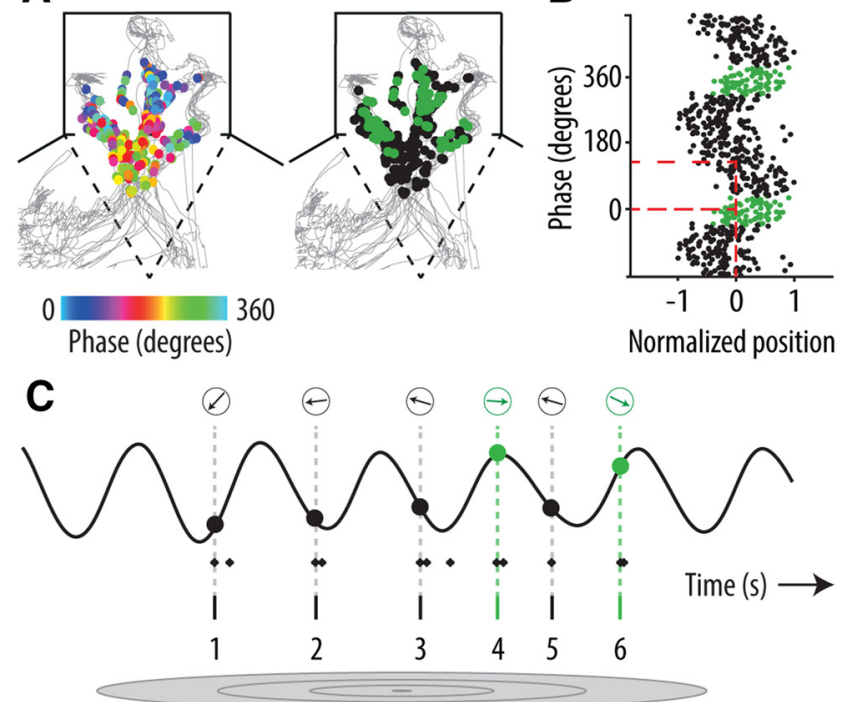

D

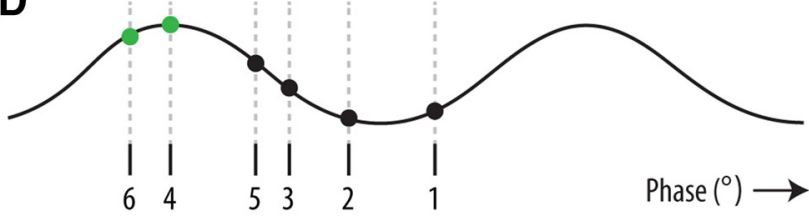

E

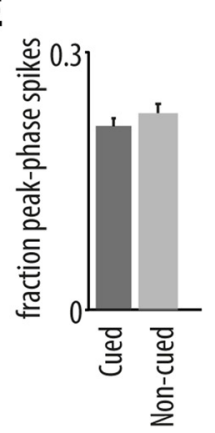

$\mathbf{F}$

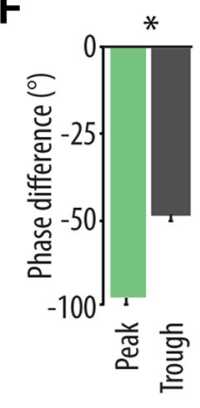

Figure 7. Hippocampal peak phase spikes emitted during cued and noncued trials. $A$, Spatial phase distributions of spikes of a hippocampal neuron that were fired during several theta cycles. Left, Spikes that are plotted on top of the rat's trajectory (gray) are color-coded for phase (peak of cycle is $0^{\circ}$; time interval: 4 s centered on chamber entry; all chambers are pooled; see Materials and Methods). Right, Spatial distribution of regular (black) and peak phase (green, phase range $\left[-40^{\circ}, 40^{\circ}\right]$ ) spikes. $B$, Firing phase of regular (black) and peak phase (green) spikes as a function of linearized and normalized position of the example neuron shown in $\boldsymbol{A}$. Red dashed lines indicate that spikes fired at position 0 , which is the center of the firing field, occur on both the descending and the peak phase of the theta cycle. $C$, Example of a recorded hippocampal neuron, plotted with concomitant LFP trace filtered in the theta range $(6-12 \mathrm{~Hz})$. Diamonds below trace represent spikes. Gray oval (bottom) represents place field of the neuron. Opaque dots and arrows in the top row indicate the phase of the first spike of a train. Green dots represent peak phase spikes. These spikes (4 and 6 ) conform to theta phase precession but are intermitted by spikes not conforming to theta phase precession (spike 5). Notice the large phase jump from spike 3 to spike 4 within the range of 2 theta cycles. D, Spikes $1-6$ are collapsed into a single theta cycle, now rendered in the phase domain. $\boldsymbol{E}$, Mean number of peak phase spikes per trial as fraction of the total spikes emitted during cued versus noncued trials ( \pm SEM; not significant). $\boldsymbol{F}$, The phase distance between the peak phase spikes and their preceding nearest neighboring spikes (green) is significantly larger than the phase distance of trough phase spikes and their prior nearest neighbors (gray; control), indicating that peak phase spikes and the associated phase jumps are a consistent feature of phase coding. ${ }^{*} p=10^{-17}$ (Wilcoxon's rank sum test). dard phase precession analysis. We labeled the spike population occurring near the peak of the theta cycle "peak phase spikes." Peak phase spikes may participate in theta phase precession because they often follow spikes that were emitted at later phases of theta in foregoing cycles (Fig. 7C,D; spikes 4 and 6), although with a large phase difference relative to the previous spike (spikes 3 and 5, respectively). Peak phase spikes are often followed by spikes on the descending slope, which do not demonstrably conform to theta phase precession (Fig. 7C,D; spike 5). We found that the number of peak phase spikes was equally distributed between cued and noncued conditions (Fig. 7E). To assess the significance of peak phase spikes and their suspected large phase difference to the previous spike ("phase jumps") to phase precession, we computed the phase difference between each peak phase spike $\left(\left[-40^{\circ}, 40^{\circ}\right]\right.$ relative to the theta peak) and the temporally nearest spike that was emitted before the peak phase spike and compared this with the phase difference between each spike that was emitted in the troughs of theta $\left(\left[140^{\circ}, 220^{\circ}\right]\right.$ relative to the theta peak) and its nearest-neighbor spike with emitted before the trough spike under scrutiny. Spikes within $15 \mathrm{~ms}$ of a peak or trough spike and spikes with a positive phase delay (i.e., nonprecessing spikes) were not taken into account. The peak phase spikes showed on average a larger negative phase difference with their nearest neighboring spike than the trough phase spikes (Wilcoxon's rank sum test, $p=10^{-17}$; Fig. $7 F$ ) indicating that the phase jumps associated to peak phase spikes are a consistent factor in phase precession. Results were similar for cued (Fig. 7F) and noncued conditions. Including also spikes with a positive phase delay relative to the peak or trough spike yielded comparable results. Together, these results indicate that (1) phase precession is a robust coding mechanism that generally applies across both cue-motivated and spontaneous behaviors, and (2) the range of theta phase precession is greater than previously reported. Also peak phase spikes are included in this phenomenon, exhibiting large "phase jumps" relative to spikes in foregoing cycles.

\section{Hippocampal beta band activity coheres with modulation of ventral striatal activity}

Probing the impact of altered hippocampal synchrony on a target area, we tested whether neuronal activity in the ventral striatum coheres with changes in hippocampal dynamics. Particularly low-frequency LFP activity recorded from ventral striatum may be susceptible to volume conduction effects arising from distant brain areas, such as the hippocampus (Sirota et al., 2008). Indeed, we found that a seemingly strong hippocampal-ventral striatal LFP coherence in the theta and beta bands vanished when the LFP signals were rereferenced to the locally averaged LFP (see Materials and Methods; this does not imply per se that no physiological coherence exists at the LFP level, but given the lack of sufficient locally recorded LFP differences, such coherence cannot be demonstrated). Ventral striatal firing patterns, however, are not susceptible to this problem, prompting us to investigate phase locking between the spike trains of 195 ventral striatal units and hippocampal LFPs. Ventral striatal firing was modulated by both theta and beta band activity in 115 (59\%) and 50 (26\%) of 195 neurons, respectively (Fig. $8 A, B$ ). These numbers were lower than for hippocampal area CA1 in both frequency bands, as expected from a limited connection strength and partially indirect projection (Groenewegen et al., 1987). Consistent with hippocampal results, spike-field coherence in the theta and beta band was enhanced in close temporal proximity to chamber en- 


\section{A Ventral Striatum}

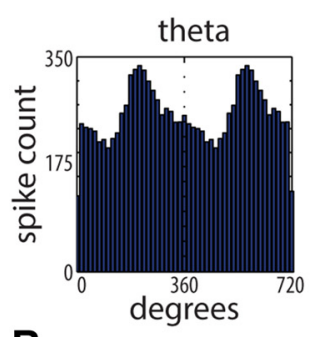

B

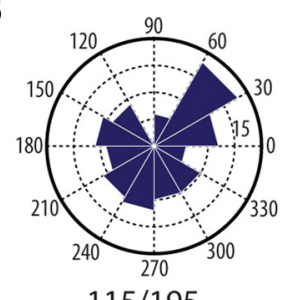

$115 / 195$
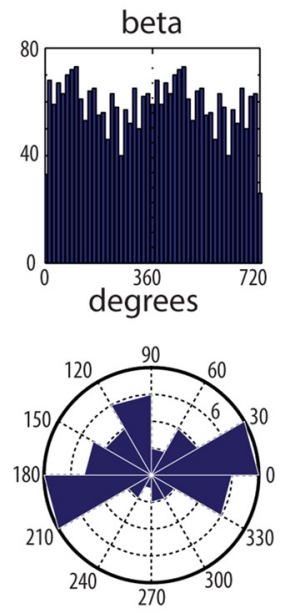

50/195 neurons
C
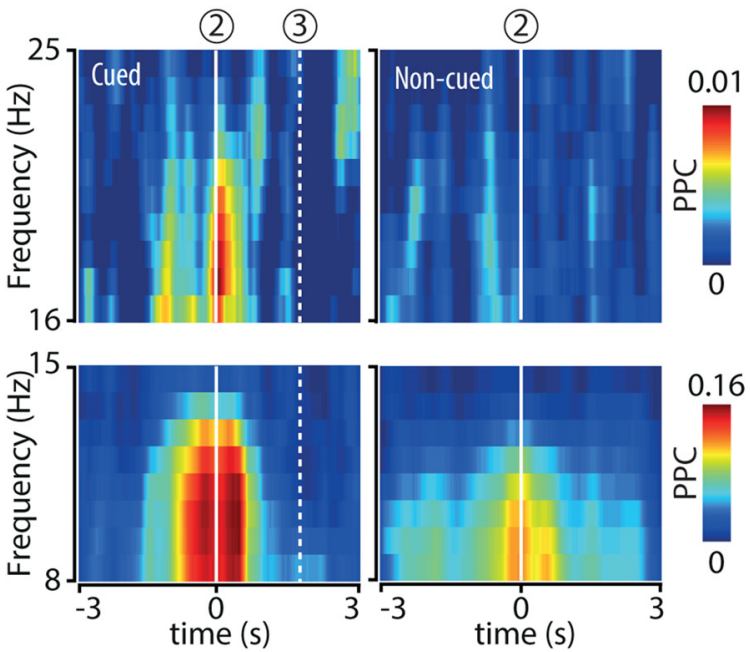

D

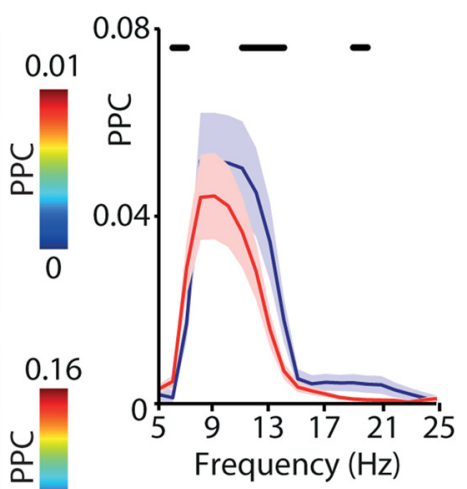

Frequency $(\mathrm{Hz})$

Figure 8. Ventral striatal phase locking to theta and beta band activity at cued chamber entries. Plotting conventions as in Figure 5 . $\boldsymbol{A}$, Phase distributions of two example ventral striatal units relative to theta (left) and beta (right) cycles recorded in the hippocampal fissure. $B$, Distributions of preferred firing angles of all significantly phase-locked units per frequency range (Rayleigh test, $\left.p<10^{-20}\right)$. C, Color-coded time-frequency plots represent mean spike-field coherence (PPC) across all recorded sessions $(n=23)$ aligned to chamber entry (2). $D$, PPC distributions as a function of frequency (mean \pm SEM) for cued (blue) and noncued (red) approaches calculated over a time window of $1 \mathrm{~s}$ centered at chamber entry. Horizontal black bars represent a significant difference between conditions (WMPSR; $p<0.05$ ).

tries and was significantly stronger during cued compared with noncued conditions (Fig. 8C,D).

\section{Discussion}

In this Y-maze task, which contrasted goal-directed navigation triggered by reward-predictive cues with uncued but similar behavior, hippocampal rhythmicity was strongly modulated by the concurrent motivational state of the rat. When reward expectancy was raised by cues, approach to goal sites was accompanied by enhanced theta and especially beta band activity in hippocampal LFPs, compared with uncued approaches (Fig. 1). Periods of enhanced theta and beta band activity were associated with increased synchronization between CA1 LFPs recorded at different locations (Fig. 2) and between LFPs and firing of single pyramidal neurons (Figs. 4, 5). In general, phase precession involved spikes emitted around the peaks of theta, which exhibited large "phase precessing jumps" relative to spikes in foregoing cycles (Figs. 6, 7). However, no modulation of theta phase precession by reward expectancy was found. The strengthened hippocampal synchronization was coexpressed in the connected ventral striatum as a stronger phase-locked firing of single units to hippocampal theta and beta band activity (Fig. 8).

\section{Enhanced rhythmic activity during goal-directed action}

Theta and beta band activity were most powerfully expressed, not when reward expectancy was directly raised by cue appearance (Fig. 2A,B), but when the animal had already initiated its approach action, entering the chamber of interest (Figs. 12-3, 5). This coupling of strengthened theta and emerging beta band activity with cue-induced action, jointly with beta-synchronized firing (Figs. $4 A-C, 5$ ), suggests that beta band activity intensifies hippocampal processing when the agent needs to combine motivation derived from predictive stimuli with navigation toward goals, potentially to map its direct action path and currently encountered sensory features in great detail (compare Hollup et al., 2001; Johnson et al., 2007; Lansink et al., 2012; Pfeiffer and Foster, 2013; Pezzulo et al., 2014). This view is partially in line with the proposal by Engel and Fries (2010) that beta activity may serve to maintain cognitive set in a top-down manner, as reward expectancy may well contribute to cognitive set. However, like beta band activity in the striatum (Leventhal et al., 2012), our hippocampal data deviate from this framework because the motivational cues in our task did not induce beta activity by themselves but only when coupled to locomotor action.

\section{Diversity of beta band activity in hippocampal-striatal systems}

We found beta band activity in the $15-20 \mathrm{~Hz}$ range, which was tightly coupled to the theta rhythm (Figs. $1 F, G, 4 D, E$ ). These aspects of beta activity appear to be different from hippocampal, cortical, or striatal beta oscillations described earlier. For example, Igarashi et al. (2014) found a $20-40 \mathrm{~Hz}$ beta coherence between hippocampus and entorhinal cortex. Rangel et al. (2015) reported that a beta band power $(15-20 \mathrm{~Hz})$ increase in the hippocampal dentate gyrus was accompanied by a concurrent theta band power decrease. An $\sim 20 \mathrm{~Hz}$ striatal beta activity was characterized as an independent state, distinct from theta oscillations (Berke, 2009). Functionally, these and the current reported types of beta band activity seem to be in some way associated with the processing of behaviorally meaningful cues. However, Berke et al. (2008) showed a 23-30 Hz beta activity in mouse hippocampus that was correlated with novelty.

CA1 [15-20] Hz beta band has received relatively limited attention (Terrazas et al., 2005), possibly because this type of beta band activity is only weakly present under conditions in which hippocampal dynamics were often investigated: that is, during spatial exploration that is either spontaneous (Vanderwolf, 1969) or motivated by unpredictable, spatially scattered food reward ("pellet-chasing"; Wilson and McNaughton, 1993; Skaggs et al., 1996; Huxter et al., 2008) and do not include temporally discrete cues. In rat CA1 LFPs obtained during a pellet-chasing paradigm, we observed beta band power levels that were comparable to the noncued condition in the current study (J.J. Bos, M.A.V., and C.M.A.P.; unpublished data). 


\section{Origins of reward expectancy effects in the hippocampus}

It is unclear which sources supply the hippocampus with motivational information during ongoing actions. This information may be provided by a hippocampal dopamine signal generated through ventral tegmental afferents to CA1 (Groenewegen et al., 1993; Zahm, 2000). Dopamine signals, however, are expected to arrive in the hippocampus at cue onset, as earliest predictor of reward (Mirenowicz and Schultz, 1994) and not during cuetriggered action. Another source may be the medial prefrontal cortex, in which the single-unit firing patterns correlate with reward-associated action sequences (Mulder et al., 2003) and which can exert population effects on several brain areas, including ventral striatum and VTA (Ferenczi et al., 2016). Moreover, reward expectancy signals coded by striatal neurons (Schultz et al., 1992; Roitman et al., 2005; Lansink et al., 2008) may reenter the corticolimbic system via the ventral pallidal-mediodorsal thalamic route (Zahm and Brog, 1992; Groenewegen et al., 1997). Furthermore, the indirect projection from the medial prefrontal cortex to hippocampus via the thalamic nucleus reuniens contributes to future-path coding during goal-directed navigation (Ito et al., 2015). Alternatively, motivational information may reach the hippocampus through a circuit of emotion-related areas, including the anterior cingulate cortex and amygdala (Cardinal et al., 2002; Rajasethupathy et al., 2015). A complex pattern of projections from amygdalar nuclei to hippocampal CA subfields, subiculum, and lateral entorhinal cortex may convey the emotional salience of sensory stimuli (Robbins et al., 1989; Cardinal et al., 2002). Future research must shed light on the precise composition of the brain network responsible for expectancydriven navigation.

\section{Theta phase precession includes "peak phase" spikes}

We found theta phase precession to be a robust coding mechanism that is stable across cued and noncued approach behaviors. Beta band activity allowed us to partition the theta cycle into two halves, of which precession was clear on the rising slope (beta-1) but not on the falling slope (beta-2; Figs. 6, 7). This is consistent with earlier evidence indicating that the phase shift seems to be less reliable near the theta peak, which thus may be thought of as giving rise to a gap in phase precession (Skaggs et al., 1996; Yamaguchi et al., 2002; Maurer et al., 2006). Temporal organization of firing patterns may be continued in this phase, however, by spikes that occurred during the peak and late ascending slope of theta but were emitted from the same spatial positions as spikes occurring on the falling slope of theta (Fig. 7). We propose that these peak-related spikes may have an additional bridging or lookahead function relative to spikes on the early ascending slope, thus linking cell assemblies that code longer sequences of positions (compare Dragoi and Buzsáki, 2006; Lisman and Redish, 2009). Here, a recorded CA1 cell is taken to represent a much larger group (assembly) of neurons coding the same position, and the specific timing of peak phase spikes is well suited to link to, and initiate, a new sequence of assemblies, covering the rising theta slope at progressively earlier phases. Maurer et al. (2006) also observed heterogeneous phase distributions of single-cell spikes within the theta cycle, but these were ascribed to cells expressing multiple place fields, thus participating in more than one assembly. In contrast, our findings show that neurons with unitary place fields generate spikes that "jump ahead" to continue precession in the transitional peak zone of theta (Fig. 7), thereby opening a time window to fit in more sequential assemblies than in the conventional scheme, and thus potentially coding more remote places or important events, such as upcoming rewards (Wikenheiser and Redish, 2015; but see Grieves et al., 2016).

\section{Impact of hippocampal theta and beta activity on target areas}

Our results suggest that the continuation of structured CA1 firing across the theta cycle, as manifested by peak phase spikes, reduces the portion of temporally unstructured activity that is transmitted to targets, such as the ventral striatum. Enhanced theta and beta band processing was coexpressed in the hippocampus and ventral striatum, as shown by phase locking and phase modulation of the firing rate of individual ventral striatal neurons (Fig. 8). Combined with previous findings on theta-modulated ventral striatal firing (Lansink et al., 2009; van der Meer and Redish, 2011), our findings suggest that navigation in theta-mode provides a baseline process in which ventral striatum (and potentially other hippocampal targets) are regularly supplied with hippocampal updates on spatial-contextual positions that are integrated to guide spontaneous or habitual locomotion. We propose that the induction of a combined hippocampal theta-beta rhythm upon reward-predictive cues and response initiation constitutes a second process, manifest in LFP coherence and beta band firing (Figs. 2, 4, 5) by which the hippocampus may gain prioritized access to systems regulating behavioral output. The neural basis of such a gain effect may lie both in the overall enhanced excitability of CA1 neuronal subsets (Fig. 4) and in the temporally structured dynamics by which spike trains of CA1 are propagated to output areas, such as subiculum and ventral striatum (Groenewegen et al., 1987; Pennartz et al., 1994). This proposal awaits further testing in experiments examining the causal role of hippocampal theta and beta band activity in modulating goal-directed actions. Given the correlative nature of the current findings, such experiments are also needed to reveal whether beta-band modulated firing in the ventral striatum exclusively depends on hippocampal output or on a larger network of afferent structures (Pennartz et al., 1994; Voorn et al., 2004).

Together, these results provide a more versatile and flexible picture of hippocampal dynamics and its impact on motivated behavior than previously suggested by findings on theta and gamma rhythmicity. Cues that raise reward expectancy induce a combined theta-beta band mode in both hippocampus and ventral striatum once goal-directed navigation has been initiated. The coupling between hippocampal beta band activity and phase modulated ventral striatal firing underscores its relevance for the guidance of motivated behaviors (Ito et al., 2008). These results raise further questions on mechanisms of theta phase sequencing: computational studies will be needed to account for the emergence of combined theta-beta band activity, peak phase spikes, and phase jumps in dual-oscillator as well as attractor type of models (Tsodyks et al., 1996; Wallenstein and Hasselmo, 1997; Mehta et al., 2002; Geisler et al., 2007; Burgess, 2008).

\section{References}

Apicella P, Ljungberg T, Scarnati E, Schultz W (1991) Responses to reward in monkey dorsal and ventral striatum. Exp Brain Res 85:491-500. Medline

Berke JD (2009) Fast oscillations in cortical-striatal networks switch frequency following rewarding events and stimulant drugs. Eur J Neurosci 30:848-859. CrossRef Medline

Berke JD, Hetrick V, Breck J, Greene RW (2008) Transient 23-30 Hz oscillations in mouse hippocampus during exploration of novel environments. Hippocampus 18:519-529. CrossRef Medline

Bosman CA, Lansink CS, Pennartz CM (2014) Functions of $\gamma$-band synchronization in cognition: from single circuits to functional diversity across cortical and subcortical systems. Eur J Neurosci 39:1982-1999. CrossRef Medline 
Bragin A, Jandó G, Nádasdy Z, Hetke J, Wise K, Buzsáki G (1995) Gamma $(40-100 \mathrm{~Hz})$ oscillation in the hippocampus of the behaving rat. J Neurosci 15:47-60. Medline

Burgess N (2008) Grid cells and $\theta$ as oscillatory interference: theory and predictions. Hippocampus 18:1157-1174. CrossRef Medline

Cardinal RN, Parkinson JA, Hall J, Everitt BJ (2002) Emotion and motivation: the role of the amygdala, ventral striatum, and prefrontal cortex. Neurosci Biobehav Rev 26:321-352. CrossRef Medline

Cei A, Girardeau G, Drieu C, Kanbi KE, Zugaro M (2014) Reversed $\theta$ sequences of hippocampal cell assemblies during backward travel. Nat Neurosci 17:719-724. CrossRef Medline

Dalley JW, Lääane K, Theobald DE, Armstrong HC, Corlett PR, Chudasama Y, Robbins TW (2005) Time-limited modulation of appetitive Pavlovian memory by D1 and NMDA receptors in the nucleus accumbens. Proc Natl Acad Sci U S A 102:6189-6194. CrossRef Medline

Dragoi G, Buzsáki G (2006) Temporal encoding of place sequences by hippocampal cell assemblies. Neuron 50:145-157. CrossRef Medline

Engel AK, Fries P (2010) $\beta$-band oscillations: signalling the status quo? Curr Opin Neurobiol 20:156-165. CrossRef Medline

Engel AK, König P, Kreiter AK, Singer W (1991) Interhemispheric synchronization of oscillatory neuronal responses in cat visual cortex. Science 252:1177-1179. CrossRef Medline

Fenton AA, Lytton WW, Barry JM, Lenck-Santini PP, Zinyuk LE, Kubík S, Bures J, Poucet B, Muller RU, Olypher AV (2010) Attention-like modulation of hippocampus place cell discharge. J Neurosci 30:4613-4625. CrossRef Medline

Ferenczi EA, Zalocusky KA, Liston C, Grosenick L, Warden MR, Amatya D, Katovich K, Mehta H, Patenaude B, Ramakrishnan C, Kalanithi P, Etkin A, Knutson B, Glover GH, Deisseroth K (2016) Prefrontal cortical regulation of brainwide circuit dynamics and reward-related behavior. Science 351:aac9698. CrossRef Medline

Frank LM, Brown EN, Wilson M (2000) Trajectory encoding in the hippocampus and entorhinal cortex. Neuron 27:169-178. CrossRef Medline

Fries P (2005) A mechanism for cognitive dynamics: neuronal communication through neuronal coherence. Trends Cogn Sci 9:474-480. CrossRef Medline

Geisler C, Robbe D, Zugaro M, Sirota A, Buzsáki G (2007) Hippocampal place cell assemblies are speed-controlled oscillators. Proc Natl Acad Sci U S A 104:8149-8154. CrossRef Medline

Grieves RM, Wood ER, Dudchenko PA (2016) Place cells on a maze encode routes rather than destinations. eLife 5:piie15986. CrossRef Medline

Groenewegen HJ, Vermeulen-Van der Zee E, te Kortschot A, Witter MP (1987) Organization of the projections from the subiculum to the ventral striatum in the rat: a study using anterograde transport of Phaseolus vulgaris leucoagglutinin. Neuroscience 23:103-120. CrossRef Medline

Groenewegen HJ, Berendse HW, Haber SN (1993) Organization of the output of the ventral striatopallidal system in the rat: ventral pallidal efferents. Neuroscience 57:113-142. CrossRef Medline

Groenewegen HJ, Wright CI, Uylings HB (1997) The anatomical relationships of the prefrontal cortex with limbic structures and the basal ganglia. J Psychopharmacol 11:99-106. CrossRef Medline

Harris KD, Csicsvari J, Hirase H, Dragoi G, Buzsáki G (2003) Organization of cell assemblies in the hippocampus. Nature 424:552-556. CrossRef Medline

Hasselmo ME (2005) What is the function of hippocampal $\theta$ rhythm? Linking behavioral data to phasic properties of field potential and unit recording data. Hippocampus 15:936-949. CrossRef Medline

Hollup SA, Kjelstrup KG, Hoff J, Moser MB, Moser EI (2001) Impaired recognition of the goal location during spatial navigation in rats with hippocampal lesions. J Neurosci 21:4505-4513. Medline

Huxter JR, Senior TJ, Allen K, Csicsvari J (2008) $\theta$ phase specific codes for two-dimensional position, trajectory and heading in the hippocampus. Nat Neurosci 11:587-594. CrossRef Medline

Igarashi KM, Lu L, Colgin LL, Moser MB, Moser EI (2014) Coordination of entorhinal-hippocampal ensemble activity during associative learning. Nature 510:143-147. CrossRef Medline

Ito HT, Zhang SJ, Witter MP, Moser EI, Moser MB (2015) A prefrontalthalamo-hippocampal circuit for goal-directed spatial navigation. Nature 522:50-55. CrossRef Medline

Ito R, Robbins TW, Pennartz CM, Everitt BJ (2008) Functional interaction between the hippocampus and nucleus accumbens shell is necessary for the acquisition of appetitive spatial context conditioning. J Neurosci 28: 6950-6959. CrossRef Medline

Jensen O, Lisman JE (1996) Hippocampal CA3 region predicts memory sequences: accounting for the phase precession of place cells. Learn Mem 3:279-287. CrossRef Medline

Johnson A, van der Meer MA, Redish AD (2007) Integrating hippocampus and striatum in decision-making. Cur Opin Neurobiol 17:692-697. CrossRef Medline

Kempter R, Leibold C, Buzsáki G, Diba K, Schmidt R (2012) Quantifying circular-linear associations: hippocampal phase precession. J Neurosci Methods 207:113-124. CrossRef Medline

Kennedy PJ, Shapiro ML (2009) Motivational states activate distinct hippocampal representations to guide goal-directed behaviors. Proc Natl Acad Sci U S A 106:10805-10810. CrossRef Medline

Kraus BJ, Robinson RJ 2nd, White JA, Eichenbaum H, Hasselmo ME (2013) Hippocampal "time cells": time versus path integration. Neuron 78: 1090-1101. CrossRef Medline

Lansink CS, Bakker M, Buster W, Lankelma J, van der Blom R, Westdorp R, Joosten RN, McNaughton BL, Pennartz CM (2007) A split microdrive for simultaneous multi-electrode recordings from two brain areas in awake small animals. J Neurosci Methods 162:129-138. CrossRef Medline

Lansink CS, Goltstein PM, Lankelma JV, Joosten RN, McNaughton BL, Pennartz CM (2008) Preferential reactivation of motivationally relevant information in the ventral striatum. J Neurosci 28:6372-6382. CrossRef Medline

Lansink CS, Goltstein PM, Lankelma JV, McNaughton BL, Pennartz CM (2009) Hippocampus leads ventral striatum in replay of place-reward information. PLoS Biol 7:e1000173. CrossRef Medline

Lansink CS, Jackson JC, Lankelma JV, Ito R, Robbins TW, Everitt BJ, Pennartz CM (2012) Reward cues in space: commonalities and differences in neural coding by hippocampal and ventral striatal ensembles. J Neurosci 32:12444-12459. CrossRef Medline

Leutgeb S, Leutgeb JK, Barnes CA, Moser EI, McNaughton BL, Moser MB (2005) Independent codes for spatial and episodic memory in hippocampal neuronal ensembles. Science 309:619-623. CrossRef Medline

Leventhal DK, Gage GJ, Schmidt R, Pettibone JR, Case AC, Berke JD (2012) Basal ganglia $\beta$ oscillations accompany cue utilization. Neuron 73:523536. CrossRef Medline

Lisman J, Redish AD (2009) Prediction, sequences and the hippocampus. Philos Trans R Soc Lond B Biol Sci 364:1193-1201. CrossRef Medline

Markus EJ, Qin YL, Leonard B, Skaggs WE, McNaughton BL, Barnes CA (1995) Interactions between location and task affect the spatial and directional firing of hippocampal neurons. J Neurosci 15:7079-7094. Medline

Martin C, Beshel J, Kay LM (2007) An olfacto-hippocampal network is dynamically involved in odor-discrimination learning. J Neurophysiol 98: 2196-2205. CrossRef Medline

Maurer AP, Cowen SL, Burke SN, Barnes CA, McNaughton BL (2006) Organization of hippocampal cell assemblies based on $\theta$ phase precession. Hippocampus 16:785-794. CrossRef Medline

Mehta MR, Lee AK, Wilson MA (2002) Role of experience and oscillations in transforming a rate code into a temporal code. Nature 417:741-746. CrossRef Medline

Milner B, Squire LR, Kandel ER (1998) Cognitive neuroscience and the study of memory. Neuron 20:445-468. CrossRef Medline

Mirenowicz J, Schultz W (1994) Importance of unpredictability for reward responses in primate dopamine neurons. J Neurophysiol 72:1024-1027. Medline

Mizuseki K, Sirota A, Pastalkova E, Buzsáki G (2009) $\theta$ oscillations provide temporal windows for local circuit computation in the entorhinalhippocampal loop. Neuron 64:267-280. CrossRef Medline

Montgomery SM, ßncur MI, Buzsáki G (2009) Behavior-dependent coordination of multiple $\theta$ dipoles in the hippocampus. J Neurosci 29:13811394. CrossRef Medline

Mulder AB, Nordquist RE, Orgüt O, Pennartz CM (2003) Learning-related changes in response patterns of prefrontal neurons during instrumental conditioning. Behav Brain Res 146:77-88. CrossRef Medline

Muller RU, Kubie JL (1987) The effects of changes in the environment on the spatial firing of hippocampal complex-spike cells. J Neurosci 7:19511968. Medline

O’Keefe J, Dostrovsky J (1971) The hippocampus as a spatial map: prelim- 
inary evidence from unit activity in the freely-moving rat. Brain Res 34: 171-175. CrossRef Medline

O’Keefe J, Recce ML (1993) Phase relationship between hippocampal place units and the EEG $\theta$ rhythm. Hippocampus 3:317-330. CrossRef Medline

Oostenveld R, Fries P, Maris E, Schoffelen JM (2011) FieldTrip: Open source software for advanced analysis of MEG, EEG, and invasive electrophysiological data. Comput Intell Neurosci 2011:156869. CrossRef Medline

Pennartz CM, Groenewegen HJ, Lopes da Silva FH (1994) The nucleus accumbens as a complex of functionally distinct neuronal ensembles: an integration of behavioural, electrophysiological and anatomical data. Progr Neurobiol 42:719-761. CrossRef Medline

Pennartz CM, Ito R, Verschure PF, Battaglia FP, Robbins TW (2011) The hippocampal-striatal axis in learning, prediction and goal-directed behavior. Trends Neurosci 34:548-559. CrossRef Medline

Pezzulo G, van der Meer MA, Lansink CS, Pennartz CM (2014) Internally generated sequences in learning and executing goal-directed behavior. Trends Cogn Sci 18:647-657. CrossRef Medline

Pfeiffer BE, Foster DJ (2013) Hippocampal place-cell sequences depict future paths to remembered goals. Nature 497:74-79. CrossRef Medline

Rajasethupathy P, Sankaran S, Marshel JH, Kim CK, Ferenczi E, Lee SY, Berndt A, Ramakrishnan C, Jaffe A, Lo M, Liston C, Deisseroth K (2015) Projections from neocortex mediate top-down control of memory retrieval. Nature 526:653-659. CrossRef Medline

Rangel LM, Chiba AA, Quinn LK (2015) $\theta$ and $\beta$ oscillatory dynamics in the dentate gyrus reveal a shift in network processing state during cue encounters. Front Sys Neurosci 9:96. CrossRef Medline

Robbins TW, Cador M, Taylor JR, Everitt BJ (1989) Limbic-striatal interactions in reward-related processes. Neurosci Biobehav Rev 13:155-162. CrossRef Medline

Roitman MF, Wheeler RA, Carelli RM (2005) Nucleus accumbens neurons are innately tuned for rewarding and aversive taste stimuli, encode their predictors, and are linked to motor output. Neuron 45:587-597. CrossRef Medline

Schultz W, Apicella P, Scarnati E, Ljungberg T (1992) Neuronal activity in monkey ventral striatum related to the expectation of reward. J Neurosci 12:4595-4610. Medline

Sirota A, Montgomery S, Fujisawa S, Isomura Y, Zugaro M, Buzsáki G (2008) Entrainment of neocortical neurons and $\gamma$ oscillations by the hippocampal $\theta$ rhythm. Neuron 60:683-697. CrossRef Medline

Skaggs WE, McNaughton BL (1996) Replay of neuronal firing sequences in rat hippocampus during sleep following spatial experience. Science 271: 1870-1873. CrossRef Medline

Skaggs WE, McNaughton BL, Wilson MA, Barnes CA (1996) $\theta$ phase precession in hippocampal neuronal populations and the compression of temporal sequences. Hippocampus 6:149-172. CrossRef Medline

Terrazas A, Krause M, Lipa P, Gothard KM, Barnes CA, McNaughton BL
(2005) Self-motion and the hippocampal spatial metric. J Neurosci 25 8085-8096. CrossRef Medline

Tsodyks MV, Skaggs WE, Sejnowski TJ, McNaughton BL (1996) Population dynamics and $\theta$ rhythm phase precession of hippocampal place cell firing: a spiking neuron model. Hippocampus 6:271-280. CrossRef Medline

van der Meer MA, Redish AD (2011) $\theta$ phase precession in rat ventral striatum links place and reward information. J Neurosci 31:2843-2854. CrossRef Medline

Vanderwolf CH (1969) Hippocampal electrical activity and voluntary movement in the rat. Electroencephalogr Clin Neurophysiol 26:407-418. CrossRef Medline

Vinck M, van Wingerden M, Womelsdorf T, Fries P, Pennartz CM (2010) The pairwise phase consistency: a bias-free measure of rhythmic neuronal synchronization. Neuroimage 51:112-122. CrossRef Medline

Vinck M, Oostenveld R, van Wingerden M, Battaglia F, Pennartz CM (2011) An improved index of phase synchronization for electrophysiological data in the presence of volume-conduction, noise and sample-size bias. Neuroimage 55:1548-1565. CrossRef Medline

Vinck M, Battaglia FP, Womelsdorf T, Pennartz C (2012) Improved measures of phase coupling between spikes and the Local Field Potential. J Comput Neurosci 33:53-75. CrossRef Medline

Voorn P, Vanderschuren LJ, Groenewegen HJ, Robbins TW, Pennartz CM (2004) Putting a spin on the dorsal-ventral divide of the striatum. Trends Neurosci 27:468-474. CrossRef Medline

Wallenstein GV, Hasselmo ME (1997) GABAergic modulation of hippocampal population activity: sequence learning, place field development, and the phase precession effect. J Neurophysiol 78:393-408. Medline

Wikenheiser AM, Redish AD (2015) Hippocampal $\theta$ sequences reflect current goals. Nat Neurosci 18:289-294. CrossRef Medline

Wilson MA, McNaughton BL (1993) Dynamics of the hippocampal ensemble code for space. Science 261:1055-1058. CrossRef Medline

Wood ER, Dudchenko PA, Robitsek RJ, Eichenbaum H (2000) Hippocampal neurons encode information about different types of memory episodes occurring in the same location. Neuron 27:623-633. CrossRef Medline

Wyble BP, Hyman JM, Rossi CA, Hasselmo ME (2004) Analysis of $\theta$ power in hippocampal EEG during bar pressing and running behavior in rats during distinct behavioral contexts. Hippocampus 14:662-674. CrossRef Medline

Yamaguchi Y, Aota Y, McNaughton BL, Lipa P (2002) Bimodality of $\theta$ phase precession in hippocampal place cells in freely running rats. J Neurophysiol 87:2629-2642. Medline

Zahm DS (2000) An integrative neuroanatomical perspective on some subcortical substrates of adaptive responding with emphasis on the nucleus accumbens. Neurosci Biobehav Rev 24:85-105. CrossRef Medline

Zahm DS, Brog JS (1992) On the significance of subterritories in the "accumbens" part of the rat ventral striatum. Neuroscience 50:751-767. CrossRef Medline 